\title{
REVIEW
}

\section{Optimizing Polymyxin Combinations Against Resistant Gram-Negative Bacteria}

Phillip J. Bergen · Zackery P. Bulman • Cornelia B. Landersdorfer • Nicholas Smith • Justin R. Lenhard · Jürgen B. Bulitta • Roger L. Nation · Jian Li • Brian T. Tsuji

To view enhanced content go to www.infectiousdiseases-open.com Received: June 9, 2015 / Published online: December 8, 2015

(C) The Author(s) 2015. This article is published with open access at Springerlink.com

\section{ABSTRACT}

Polymyxin combination therapy is increasingly used clinically. However, systematic investigations of such combinations are a relatively recent phenomenon. The emerging pharmacodynamic (PD) and pharmacokinetic (PK) data on CMS/colistin and polymyxin B suggest that caution is required with monotherapy. Given this situation, polymyxin combination therapy has been suggested as a possible way to increase bacterial killing and reduce the development of resistance.

P. J. Bergen - C. B. Landersdorfer

Centre for Medicine Use and Safety, Monash

University, Melbourne, Australia

Z. P. Bulman · N. Smith · J. R. Lenhard .

B. T. Tsuji $(\square)$

Laboratory for Antimicrobial Pharmacodynamics,

School of Pharmacy and Pharmaceutical Sciences,

University at Buffalo, SUNY, Buffalo, NY, USA

e-mail: btsuji@buffalo.edu

C. B. Landersdorfer · R. L. Nation · J. Li

Drug Delivery, Disposition and Dynamics, Monash

Institute of Pharmaceutical Sciences, Monash

University, Parkville, Australia

J. B. Bulitta

Center for Pharmacometrics and Systems

Pharmacology, Department of Pharmaceutics,

College of Pharmacy, University of Florida, Orlando,

FL, USA
Considerable in vitro data have been generated in support of this view, particularly recent studies utilizing dynamic models. However, most existing animal data are of poor quality with major shortcomings in study design, while clinical data are generally limited to retrospective analysis and small, low-power, prospective studies. This article provides an overview of clinical and preclinical investigations of CMS/colistin and polymyxin B combination therapy.

Keywords: Colistin; Colistin methanesulfonate; Combination; Pharmacodynamic; Polymyxins; Polymyxin B

\section{INTRODUCTION}

The polymyxin antibiotics colistin [administered intravenously (IV) as colistin methanesulfonate (CMS), the sulfomethylated derivative (and prodrug [1]) of colistin] and polymyxin B were first used clinically in the 1950s. In the intervening decades, toxicity concerns following parenteral administration (primarily nephro- and neurotoxicity) led to a 
substantial decline in use [2, 3]. However, the increasing prevalence of infections caused by multidrug-resistant (MDR) Gram-negative bacteria, especially Pseudomonas aeruginosa, Acinetobacter baumannii and Klebsiella pneumoniae [4], combined with few antimicrobial agents being in development which target Gram-negative bacteria [5, 6], has led to a resurgence in interest in polymyxins as a last-line therapy. As a consequence, much research has been conducted over the last decade or so with the aim of establishing the scientific basis for their clinical use. The emerging pharmacodynamic (PD) and pharmacokinetic (PK) data on CMS/colistin and polymyxin $B$ suggest that caution is required with monotherapy. Specifically, monotherapy with these agents is unlikely to generate reliably efficacious plasma concentrations [7-10], with regrowth and the emergence of resistance commonly reported with polymyxin monotherapy even with concentrations greatly exceeding those achievable clinically [11-18]. The amplification of polymyxin-resistant subpopulations in heteroresistant isolates, i.e. isolates which are susceptible to polymyxins based upon their MICs but which contain pre-existing resistant subpopulations, is a known contributor to the observed regrowth following monotherapy, and suggestive of selective eradication of the susceptible bacterial population with unopposed regrowth of resistant subpopulations [13-24]; adaptive resistance may also contribute to regrowth [15]. Additionally, a recent study demonstrated that, in the presence of colistin, amino acid alterations in two-component systems such as PmrAB, PhoPQ and ParRS involved in polymyxin resistance (due to modifications of lipopolysaccharides in the Gram-negative cell wall) occur rapidly in vitro within the period of selection of single-step mutants [25]. This suggests polymyxin treatment may provoke genetic mutations related to resistance as a mutagen within a short period, in addition to the selection of pre-existing resistant subpopulations.

Given the emerging data above, it is not surprising that polymyxin combination therapy has been suggested as a possible way to increase antimicrobial activity and reduce the emergence of resistance [7, 26-28]. Polymyxin combinations may provide an enhanced PD effect via subpopulation synergy (the process whereby one drug kills the resistant subpopulation(s) of the other drug, and vice versa; Fig. 1a) and/or mechanistic synergy (whereby two drugs acting on different cellular pathways increase the rate or extent of killing of the other drug; Fig. 1b) [29]. Additionally, it is possible that permeabilization of the bacterial membrane by polymyxins may decrease the effect of resistance mechanisms such as efflux

A

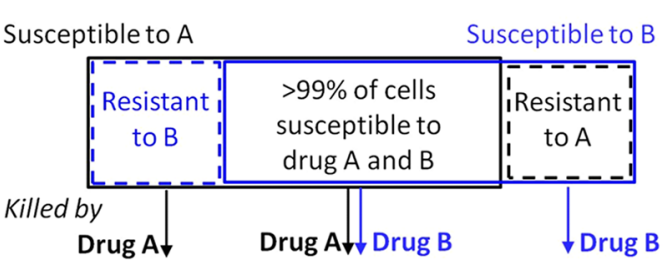

B

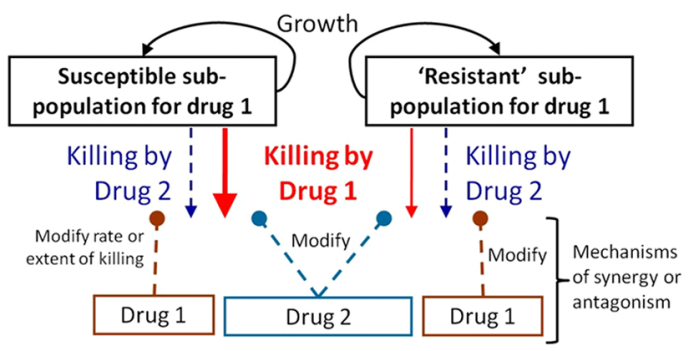

Fig. 1 Schematic representations for subpopulation synergy (a) and mechanistic synergy (b). In subpopulation synergy, drug A kills the resistant subpopulations of drug $B$, and vice versa. In mechanistic synergy for drugs acting on different cellular pathways, drug A increases the rate or extent of killing by drug B, and vice versa. Figure adapted from Bulitta et al. [29], with permission 
pumps acting on the second drug, rendering the bacterium more susceptible to the drug. While combination therapy is often employed in the hope of improving the activity of available agents when therapeutic options are limited, the choice of agents is often empirically driven and based on trial and error or personal experience. This approach is poorly guided and may lead to suboptimal patient care. Given the 'last resort' status of the polymyxins and increasing reports of resistance to these agents [30-34], systematic investigations of the effect of polymyxin combinations on bacterial killing and the emergence of polymyxin resistance are required to inform optimal dosage regimen design. This is especially the case given polymyxin combination therapy is increasingly used clinically [35-50]. Unfortunately, systematic investigations of such combinations are a relatively recent phenomenon. This review provides an overview of preclinical and clinical investigations examining CMS/colistin and polymyxin B combination therapy; other aspects of polymyxin pharmacology are reviewed elsewhere [51, 52]. This article is based on previously conducted studies and does not involve any new studies of human or animal subjects performed by any of the authors.

\section{Preclinical Investigations}

\section{In Vitro Studies}

Many in vitro studies have examined polymyxin combinations using the fractional inhibitory concentration (FIC) index and Etest methods. However, as a means of assessing the interaction of antimicrobial agents these methods are less discriminatory and/or correlate poorly with other in vitro methods, such as static (constant antibiotic concentration) or dynamic [fluctuating antibiotic concentration simulating patient pharmacokinetics (PK)] time-kill models [53-57]. In addition, time-kill methods provide a picture of antimicrobial action over time based on serial viable counts, whereas FIC and Etest methods provide only inhibitory data and are usually examined at a single time point [58]. Given this situation, results derived from FIC and Etest methods are not discussed here.

Complicating any discussion of the literature examining antimicrobial combination therapy are the definitions of synergy and antagonism employed. In time-kill studies, synergy has traditionally been defined as a 100-fold increase and antagonism a 100-fold decrease in the observed colony counts at $24 \mathrm{~h}$ [58]. However, variations on these definitions abound in the literature, complicating comparisons of effect between studies. Additionally, synergy according to the definition above is often the sole criterion by which the success of a combination is judged, with little attention given to the overall antimicrobial activity of the combination. Importantly, some investigations have used CMS, the inactive prodrug of colistin [1]; use of CMS is inappropriate in these in vitro systems given variable formation over time of the active species, colistin. Unfortunately, it is not always possible to ascertain whether colistin (sulfate) or CMS was administered. Finally, the varying breakpoints set between laboratory standards organizations for various bacterial species (Table 1), a lack of standardization of in vitro testing methods, and the limited number and clonal diversity of strains employed further complicates comparison between studies [59].

The majority of time-kill studies investigating polymyxin combinations utilize colistin, the most common second drugs being rifampicin [22, 60-68], carbapenems [17, 18, 21, 60, 61, 66, 67, 69-83], aminoglycosides [60, 84-86], glycopeptides [67, 87-92], and 


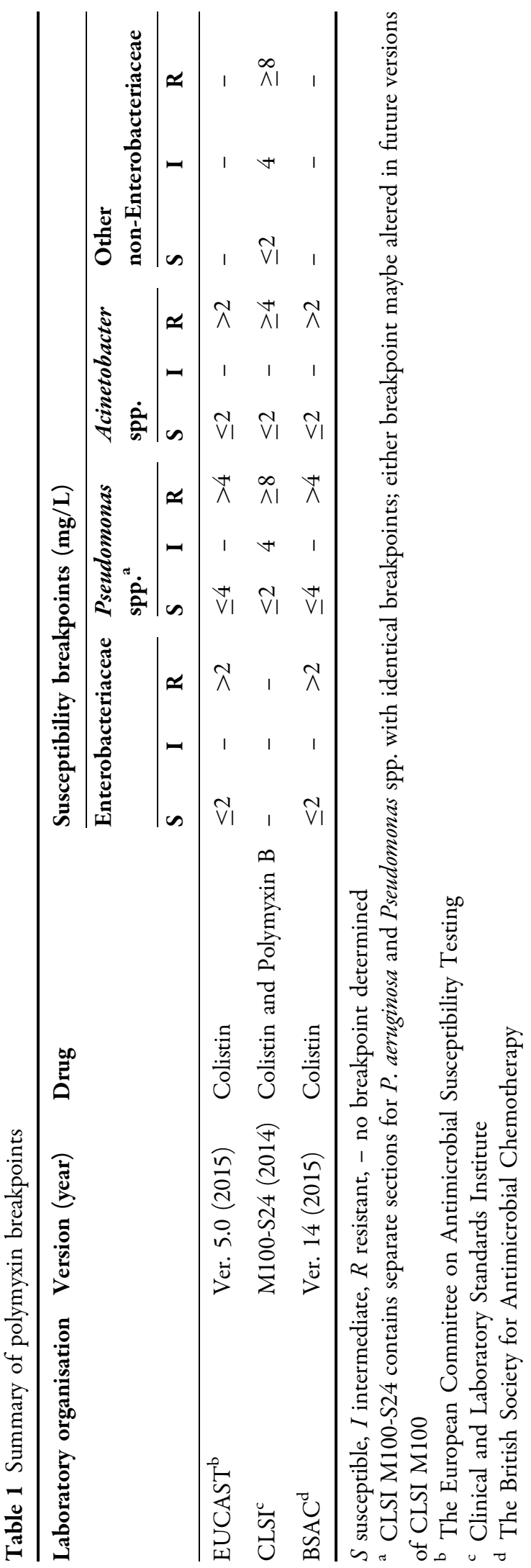

tigecycline [68, 86, 90, 93-97]. However, many other antibiotics including fosfomycin $[66,86$, 98, 99], fluoroquinolones [12, 60, 100], ampicillin/sulbactam [61], sulbactam alone [79], ceftazidime [12], daptomycin [101-103], linezolid [91], fusidic acid [104] and chloramphenicol [24] have been employed. This review will examine significant recent static and dynamic time-kill investigations with polymyxins (colistin or polymyxin B) against the most commonly studied organisms, primarily $P$. aeruginosa, $A$. baumannii and K. pneumoniae. Due to the large number of published static time-kill studies, these organisms will be considered separately in this section.

\section{Static Time-Kill Studies}

Pseudomonas aeruginosa Bergen et al. [17] investigated bacterial killing and resistance emergence over $48 \mathrm{~h}$ with nine colistin/ imipenem combinations against five clinical isolates and an ATCC reference strain of $P$. aeruginosa; strains included a mixture of colistin and imipenem susceptible and resistant strains, colistin heteroresistant and non-heteroresistant strains, and MDR and non-MDR strains. It is currently the only static time-kill investigation to examine polymyxin combinations at two inocula $\left(\sim 10^{6}\right.$ and $\sim 10^{8}$ $\mathrm{cfu} / \mathrm{mL})$. With all isolates, regrowth was observed with colistin monotherapy $(0.5 \times, 4 \times$ and $16 \times$ MIC for susceptible isolates and 1, 4 and $32 \mathrm{mg} / \mathrm{L}$ for resistant isolates). However, the addition of imipenem $(0.5 \times, 4 \times$ and $16 \times$ MIC for susceptible isolates and 1, 8 and $32 \mathrm{mg} / \mathrm{L}$ for resistant isolates) to colistin at both inocula generally resulted in substantial improvements in bacterial killing over equivalent monotherapy across the 48-h duration against MDR $P$. aeruginosa isolates resistant to either antibiotic, even those containing ESBLs. These 
benefits were evident with all colistin concentrations at the low inoculum, and $4 \times$ and 16× MIC (or 4 and $32 \mathrm{mg} / \mathrm{L}$ ) colistin at the high inoculum. Enhanced bacterial killing was less pronounced against three isolates susceptible to both antibiotics after $\sim 6 \mathrm{~h}$. At both inocula, colistin monotherapy and combination therapy resulted in similar increases in colistin-resistant subpopulations in all five colistin-susceptible isolates. It should be noted, however, that a subsequent study by the same investigators which combined colistin with doripenem in a dynamic model resulted in a dramatic reduction of colistin-resistant subpopulations with combination therapy compared with monotherapy [18]. The authors suggested this difference may be attributable to loss of imipenem due to degradation in the static experiments, with intermittent dosing of doripenem in the dynamic model replenishing concentrations.

In other studies employing $P$. aeruginosa, Pankuch et al. combined colistin with meropenem [71] or doripenem [72] at various concentrations (including sub-MIC concentrations); the proportion of multidrug-resistant (MDR) strains was not stated. Synergy was reported against 13 (25.5\%) of 51 isolates at $24 \mathrm{~h}$ with the colistin/ meropenem combinations and 19 (76.0\%) of 25 isolates with the colistin/doripenem combinations. Against five carbapenem-resistant strains of $P$. aeruginosa, none of polymyxin B, doripenem, and rifampicin as monotherapy were bactericidal (defined as a $\geq 3-\log _{10} \mathrm{cfu} / \mathrm{mL}$ decrease in $24 \mathrm{~h}$ ) at $24 \mathrm{~h}$ when used at concentrations of $0.25 \times$ MIC, although triple therapy with the combination was bactericidal against all isolates and better than dual combinations [75]; 'synergy' was not directly examined in this investigation. Di et al. [99] combined colistin with fosfomycin against five isolates of carbapenem-resistant $P$. aeruginosa (starting inoculum of $\sim 5 \times 10^{5} \mathrm{cfu} / \mathrm{mL}$ ). Each drug was used at a concentration of $0.5 \times$ or $1 \times$ MIC (i.e. two combinations tested) with the absolute concentrations (range: colistin, 0.5-4 mg/L; fosfomycin, 32-256 mg/L) being clinically achievable. Neither agent alone was significantly bactericidal. However, in combination, bacterial eradication was achieved no later than $12 \mathrm{~h}$ after commencement of therapy in 9 of 10 cases.

Acinetobacter baumannii In the two studies by Pankuch et al. discussed above, colistin was also combined with either meropenem [71] or doripenem [72] against clinical isolates of A. baumannii; the proportion of MDR strains was not stated. Colistin (0.06-8 mg/L) and meropenem (0.03-64 mg/L) showed synergy against $49(94.2 \%)$ of 52 isolates at $24 \mathrm{~h}$, whereas colistin $(0.12-16 \mathrm{mg} / \mathrm{L})$ and doripenem (0.06-32 mg/L) showed synergy against $25(100 \%)$ of 25 isolates of A. baumannii. In another study, colistin was combined with doripenem against five extensively drug-resistant (XDR; defined as resistant to all agents except polymyxins and tigecycline) isolates of A. baumannii taken from solid organ transplant recipients [105]. Against all five isolates, sub-MIC concentrations of doripenem resulted in virtually no antimicrobial activity, whereas colistin $(0.25 \times$ to $1 \times \mathrm{MIC}$ ) was bacteriostatic (inhibiting growth of the inocula without causing significant killing). However, with the combination of colistin $(0.125 x$ to $0.25 \times$ MIC) plus doripenem $(8 \mathrm{mg} / \mathrm{L})$, no viable bacteria were detected at $8 \mathrm{~h}$ with regrowth absent at $24 \mathrm{~h}$. Based on these in vitro results, this institution subsequently recommended 
combinations of CMS [5 mg/kg/day of colistin base activity (CBA; equivalent to $\sim 167,000 \mathrm{IU} /$ $\mathrm{kg}$ /day) in 2-4 divided doses] and doripenem (500 mg 8-hourly) for use in solid organ transplant recipients infected with XDR $A$. baumannii. At the time of publication, four patients had received this combination with a fifth receiving CMS plus meropenem; four $(80 \%)$ of the five patients had a positive clinical response and survived.

In a study involving 9 pairs of isolates (18 isolates in total) of XDR, A. baumannii collected from nine patients with recurrent respiratory tract infections prior to and following treatment with IV CMS plus doripenem, Oleksiuk et al. [79] examined in vitro killing using colistin (2 mg/L), doripenem ( $8 \mathrm{mg} / \mathrm{L})$, and sulbactam $(4 \mathrm{mg} / \mathrm{L})$ alone and in combination; 8 (89\%) of 9 pairs of isolates were genetically indistinguishable; sulbactam alone has been found to have intrinsic activity against Acinetobacter spp. [106], and it has even been suggested that activity of ampicillin/sulbactam against Acinetobacter spp. derives exclusively from sulbactam [107]. At $24 \mathrm{~h}$, synergy was more frequent with the colistin/doripenem combination [16 (89\%) of 18 isolates] compared to the colistin/sulbactam combination [9 (50\%) of 18 isolates], with bacterial killing of the former attenuated against isolates previously exposed to the combination in vivo [mean $\log$ kill $(\mathrm{cfu} / \mathrm{mL})$ at $24 \mathrm{~h}$ of $-5.08 \log _{10}$ vs. $-2.88 \log _{10}$ for isolates collected prior to and following antibiotic treatment, respectively]; there was no difference in the mean log kills with the colistin/sulbactam combination. Bacterial killing was further improved with the triple combination, including against isolates which had previously been exposed to colistin/doripenem in vivo and which failed to respond to the colistin/doripenem combination. While colistin/doripenem combinations were equally active against colistin-susceptible and -resistant isolates, all isolates that failed to respond to the combination had doripenem MICs $>64 \mathrm{mg} / \mathrm{L}$. A similar association between the effectiveness of a colistin/doripenem combination and the doripenem MIC of the organism has also been observed in $K$. pneumoniae carbapenemase (KPC)-producing K. pneumoniae (discussed below) [80].

More so than for any other organism, a number of antibiotics normally considered inactive against Gram-negative organisms (rifampicin, glycopeptides, daptomycin, and fusidic acid) have been used in combination with colistin against A. baumannii [61, 87, 88, $101,102,104]$. The rationale behind such unusual combinations is that the permeabilizing effect of the polymyxin on the outer membrane may facilitate the entry of antibiotics into the cytoplasm which are normally excluded by Gram-negative strains due to their large molecular size [22, 38]. Tripodi et al. [61] employed nine isolates of MDR A.baumannii producing OXA-58 carbapenemase to examine double and triple combinations of colistin $(6 \mathrm{mg} / \mathrm{L})$, rifampicin $(5 \mathrm{mg} / \mathrm{L})$, imipenem $(20 \mathrm{mg} / \mathrm{L}) \quad$ and ampicillin/sulbactam $(50 \mathrm{mg} / \mathrm{L})$. The double (colistin plus each of the second drugs) and triple (colistin/rifampicin/imipenem, or colistin/ rifampicin/ampicillin/sulbactam) combinations produced similar bacterial killing to monotherapy with colistin (the most active agent). Against five MDR-colistin-susceptible isolates of A.baumannii, colistin (1 mg/L) monotherapy produced rapid bacterial killing followed by rapid regrowth to control values by $24 \mathrm{~h}$. When colistin was combined with vancomycin $(20 \mathrm{mg} / \mathrm{L})$ [87] or teicoplanin $(20 \mathrm{mg} / \mathrm{L})$ [88], regrowth even at $48 \mathrm{~h}$ was 
suppressed against four isolates with vancomycin and all isolates with teicoplanin; with the one exception, bacterial killing at $24 \mathrm{~h}$ with each combination was $\sim 5-$ to $8-\log _{10} \mathrm{cfu} /$ $\mathrm{mL}$ greater than achieved with colistin monotherapy. While the nephrotoxic effects of both colistin and vancomycin may complicate use of this combination clinically (as will be discussed in the clinical studies section), the authors noted the lower incidence of renal toxicity of teicoplanin which may make such a combination more acceptable to clinicians [108, 109]. Recently, Phee et al. [104] observed substantial synergy between colistin $(\leq 2 \mathrm{mg} / \mathrm{L})$ and fusidic acid ( $1 \mathrm{mg} / \mathrm{L}$ or $0.5 \times \mathrm{MIC})$ against six isolates of A.baumannii, including colistin-resistant strains. The combination also prevented the emergence of colistin resistance, which was readily selected with colistin alone. Significantly enhanced bacterial killing has also been reported with colistin/daptomycin combinations against colistin-susceptible, but not colistin-resistant, isolates of A.baumannii $[101,102]$.

\section{Klebsiella pneumoniae and other} Enterobacteriaceae Pournaras et al. [93] examined colistin and tigecycline combinations against eight colistin-susceptible-KPC-2producing enterobacterial clinical strains (four K. pneumoniae, two Escherichia coli, one Enterobacter cloacae and one Serratia marcescens). Each antibiotic was tested at $1 \times, 2 \times$ and $4 \times$ MIC (range, $0.5-4 \mathrm{mg} / \mathrm{L}$ for colistin and $0.25-16 \mathrm{mg} / \mathrm{L}$ for tigecycline) with experiments conducted over $24 \mathrm{~h}$. Compared to monotherapy, bacterial killing across $24 \mathrm{~h}$ was greatly improved with the colistin/tigecycline combinations and was synergistic at $1 \times$ and $2 \times$ MIC against most organisms at 4 and $8 \mathrm{~h}$; synergy was maintained at $24 \mathrm{~h}$ against all strains at $4 \times$ MIC. Similar improvements in bacterial killing were reported by Lee and Burgess [77] with the combination of colistin or polymyxin B (both at $2 \times$ MIC, range $0.125-0.5 \mathrm{mg} / \mathrm{L}$ for colistin and $0.25-0.5 \mathrm{mg} / \mathrm{L}$ for polymyxin B) and doripenem $(6 \mathrm{mg} / \mathrm{L})$ against four polymyxin-susceptible doripenem-resistant KPC-3-producing isolates of K. pneumoniae. For all strains at $24 \mathrm{~h}$, bactericidal activity was not sustained with any monotherapy with MIC measurements at this time, indicating the development of polymyxin resistance (MICs, $8-128 \mathrm{mg} / \mathrm{L}$ ). However, bactericidal activity was maintained with both polymyxins in combination, with synergy reported at this time. At $48 \mathrm{~h}$, synergy was reported in two (50\%) of four isolates with colistin and all isolates with polymyxin $\mathrm{B}$.

In an interesting study by Clancy et al. [80], colistin $(2 \mathrm{mg} / \mathrm{L})$ was combined with doripenem $(8 \mathrm{mg} / \mathrm{L})$ against $23 \mathrm{KPC}-2$-producing strains of K. pneumoniae each containing a variant mutant opmK35 porin gene). The MICs of these isolates to each antibiotic varied extensively (range $0.125-128 \mathrm{mg} / \mathrm{L}$ for colistin and $4-256 \mathrm{mg} / \mathrm{L}$ for doripenem). For the four strains with doripenem MICs of $\leq 8 \mathrm{mg} / \mathrm{L}$, the colistin/doripenem combination was significantly more active at 12 and $24 \mathrm{~h}$ than equivalent monotherapy with either agent, with synergy reported at $24 \mathrm{~h}$ in all cases. In contrast, at $24 \mathrm{~h}$, there was no overall difference in median bacterial killing for strains with doripenem MICs $>8 \mathrm{mg} / \mathrm{L}$, nor was there a difference between strains with colistin MICs of $\leq 2 \mathrm{mg} / \mathrm{L}$ and $>2 \mathrm{mg} / \mathrm{L}$. The authors noted that isolates which contained insertions encoding glycine and aspartic acid at amino acid (aa) positions 134 and 135 (ins aa134-135 GD; $n=8$ ) and ompK36 promoter IS5mutations $(n=7)$ were associated with significantly higher 
doripenem MICs and diminished efficacy of colistin/doripenem combinations (bacterial killing more closely resembled colistin monotherapy). However, increased killing with the combination was observed with other mutant/wild-type ompK36 strains even when doripenem MICs were elevated. The authors suggested that doripenem MICs and ompK36 genotyping of KPC-K. pneumoniae may be useful for identifying strains most likely to respond to colistin/doripenem combination therapy. These results suggest that, despite membrane permeabilization potentially increasing access of doripenem to target sites, allowing it to overcome hydrolysis by KPC, OmpK36 porins may also be necessary for synergy.

In comparison to KPC-producing strains of K. pneumoniae, fewer studies have employed metallo- $\beta$-lactamase (MBL)-producing strains when examining polymyxin combination therapy. Against 42 unique clinical isolates of blaVIM-1-type MBL-producing K.pneumoniae, the combination of colistin $(5 \mathrm{mg} / \mathrm{L})$ plus imipenem $(10 \mathrm{mg} / \mathrm{L})$ resulted in synergy at $24 \mathrm{~h}$ against 12 (50\%) of 24 colistin-susceptible isolates, but antagonism was observed against $10(55.6 \%)$ of 18 colistin-resistant isolates [74]. Interestingly, at this time, resistance to colistin (MICs $64-256 \mathrm{mg} / \mathrm{L}$ ) was observed in 7 (58.3\%) of 12 isolates initially susceptible to colistin, but imipenem resistance was not observed in any of 4 isolates initially susceptible to imipenem and which showed regrowth at $24 \mathrm{~h}$. In a very large study, Tangden et al. [66] conducted over 200 time-kill experiments with 24 antibiotic regimens, including colistin $(4.0 \mathrm{mg} / \mathrm{L})$ in double and triple combinations with meropenem $(6.8 \mathrm{mg} / \mathrm{L})$, aztreonam $(17 \mathrm{mg} / \mathrm{L})$, fosfomycin $(83 \mathrm{mg} / \mathrm{L})$ and rifampicin $(1.7 \mathrm{mg} /$ L), against two VIM-1-type and two NDM-1-type K.pneumoniae strains (all colistin-susceptible; susceptibilities to the other antibiotics varied substantially). At $24 \mathrm{~h}$, the colistin/fosfomycin combination was bactericidal and synergistic against three of the four strains [both NDM-1-types (each fosfomycin-resistant) and one VIM-1-type], while the triple combination of colistin/fosfomycin/meropenem was bactericidal against three strains and synergistic against all strains. While colistin plus rifampicin was only synergistic at this time against both NDM-1-type strains, the addition of meropenem to this regimen resulted in bactericidal and synergistic activity against all strains; this triple combination was the most effective regimen overall. Recently, the combination of polymyxin B (0.5 or $2 \mathrm{mg} / \mathrm{L})$ plus chloramphenicol (range 4-32 mg/L) dramatically delayed regrowth or, in over half the combinations tested, resulted in bacterial eradication of four NDM-producing-polymyxinsusceptible strains of K. pneumoniae [24]. Finally, while a study by Albur et al. [94] found colistin or CMS combined with tigecycline did not increase bacterial killing against a range of NDM-1-producing Enterobacteriaceae, this disappointing result may have been due to the very low concentrations employed (e.g., a maximum concentration of $0.29 \mathrm{mg} / \mathrm{L}$ for colistin) [94].

\section{Dynamic Time-Kill Studies}

Few studies have utilized in vitro dynamic models when examining polymyxin combinations, with all known studies considered below. Such models simulate the time course of antibiotic concentrations in vitro. The first study undertaken in a one-compartment dynamic model was by Gunderson et al. [12] who combined colistin [steady-state peak concentrations $\left(C_{\max }\right)$ of 6 or $18 \mathrm{mg} / \mathrm{L}$ every $24 \mathrm{~h}$; half-life, $3 \mathrm{~h}$ ] with either ceftazidime (constant concentration of $50 \mathrm{mg}$ / 
L) or ciprofloxacin $\left(C_{\max } 5 \mathrm{mg} / \mathrm{L}\right.$ every $12 \mathrm{~h}$; half-life, $3 \mathrm{~h}$ ) against two colistin-susceptible MDR isolates of $P$. aeruginosa. Although synergy with colistin plus ceftazidime was reported, combination therapy was only compared to colistin monotherapy. However, in light of more recent PK data from critically ill patients or patients with cystic fibrosis (CF) [7, 9, $110-112]$, only the $6 \mathrm{mg} / \mathrm{L}$ concentration can be considered clinically achievable (and only achievable in a small number of patients). Additionally, as colistin was administered as a single dose every $24 \mathrm{~h}$, the PK profile generated is unlike that observed in either of these patient groups.

More recent studies have administered clinically achievable unbound (free) plasma concentrations of colistin as a continuous infusion [18, 21-23, 81], simulating the 'flat' profiles of formed colistin observed in critically ill patients at steady state across a CMS dosage interval [7, 111]. Three examined killing of exclusively planktonic bacteria in a one-compartment model across $72-96 \mathrm{~h}$ and utilized both a low $\left(\sim 10^{6} \mathrm{cfu} / \mathrm{mL}\right)$ and high $\left(\sim 10^{8} \mathrm{cfu} / \mathrm{mL}\right)$ inocula $[18,21,22]$, the latter mimicking the high bacterial densities found in some infections [113, 114]. Against MDR (including heteroresistant) isolates of P. aeruginosa [18] and K.pneumoniae [21], colistin (constant concentrations of 0.5 or $2 \mathrm{mg} / \mathrm{L})$ was combined with doripenem $\left(C_{\max }\right.$ of 2.5 or $25 \mathrm{mg} / \mathrm{L}$ every $8 \mathrm{~h}$; half-life, $1.5 \mathrm{~h}$ ); against MDR A.baumannii [22], colistin (constant concentrations of $0.5,2$ or $5 \mathrm{mg} / \mathrm{L}$ ) was combined with rifampicin $\left(C_{\max }\right.$ of $5 \mathrm{mg} / \mathrm{L}$ every $24 \mathrm{~h}$; half-life, $3 \mathrm{~h}$ ). A fourth study examined colistin (constant concentrations of 2 and $5 \mathrm{mg} / \mathrm{L}$ ) plus doripenem $\left(C_{\max }\right.$ of $25 \mathrm{mg} / \mathrm{L}$ every $8 \mathrm{~h}$; half-life, $1.5 \mathrm{~h}$ ) against two heteroresistant and one resistant strain of $P$. aeruginosa in a hollow-fiber infection model (inoculum $10^{9.3} \mathrm{cfu} / \mathrm{mL}$ ) across 10 days [23]. Synergy or additivity (the latter defined as a 1.0to $<2-\log _{10}$ decrease in the number of $\mathrm{cfu} / \mathrm{mL}$ between the combination and its most active component) were generally observed across the duration of the experiment even at the higher inocula. Enhanced killing was often dramatic, with no viable bacteria detected on occasions against all three bacterial species. Against $P$. aeruginosa, combinations containing colistin 0.5 or $2 \mathrm{mg} / \mathrm{L}$ plus doripenem at $C_{\max }$ of $25 \mathrm{mg} / \mathrm{L}$ (one-compartment model) resulted in eradication of a MDR colistin-resistant isolate at the low inoculum, with substantial reductions in regrowth (including to below the limit of detection at $\sim 50 \mathrm{~h}$ ) at the high inoculum (Fig. 2) [18]. Similarly, eradication was observed in the hollow-fiber model with the colistin $(5 \mathrm{mg} / \mathrm{L})$ plus doripenem regimen.

An important finding of the above investigations was that in all four studies the emergence of colistin-resistant subpopulations observed with colistin monotherapy was substantially reduced or completely suppressed with combination therapy. Interestingly, against $A$. baumannii at the low inocula some colistin/rifampicin combinations were able to reduce the pre-existing colistin-resistant subpopulations of a colistin-resistant isolate to below the limit of detection (Fig. 3). This unexpected finding suggests that this combination may suppress the emergence of de novo colistin resistance. Enhanced bacterial killing and suppression of the emergence of colistin-resistant subpopulations has also been reported with colistin (constant concentrations of 1.25 or $3.50 \mathrm{mg} / \mathrm{L})$ combined with doripenem $\left(C_{\max }\right.$ of $25 \mathrm{mg} / \mathrm{L}$ every $8 \mathrm{~h}$; half-life, $1.5 \mathrm{~h}$ ) against biofilm-embedded MDR P. aeruginosa [81]. 

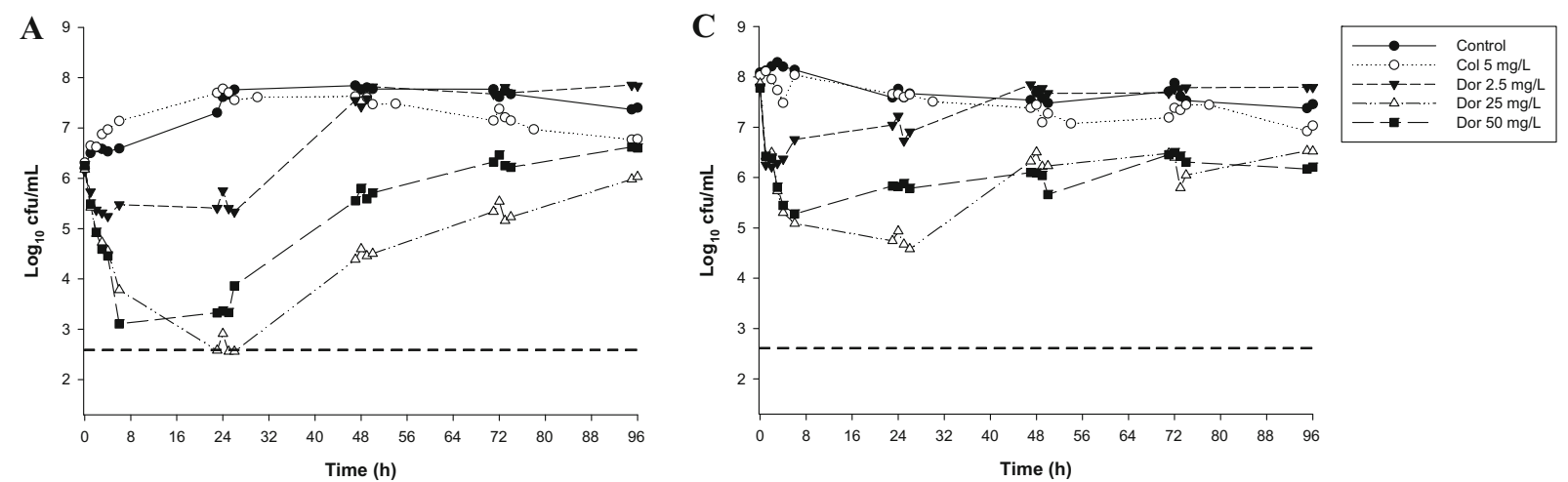

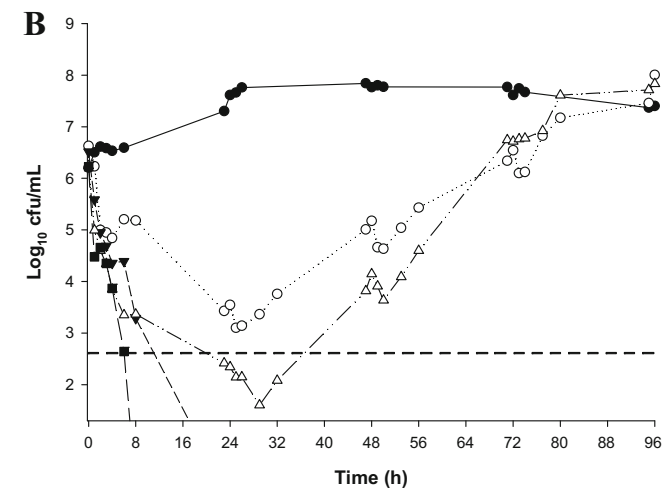

Fig. 2 Time-kill curves for colistin and doripenem monotherapy $(\mathbf{a}, \mathbf{c})$ and the combination $(\mathbf{b}, \mathbf{d})$ against a non-mucoid MDR colistin-resistant clinical isolate (19147 $\mathrm{n} / \mathrm{m})$ of $P$. aeruginosa at an inoculum of $\sim 10^{6} \mathrm{cfu} / \mathrm{mL}$ (left-hand panels) and $\sim 10^{8} \mathrm{cfu} / \mathrm{mL}$ (right-hand panels)

Collectively, the in vitro data from both static and dynamic time-kill studies show promise for several polymyxin-drug combinations. The dynamic studies in particular indicate that certain combinations (colistin plus doripenem against $P$. aeruginosa and $K$. pneumoniae; colistin plus rifampicin against A.baumannii) have the potential to substantially enhance bacterial killing and reduce (or completely suppress) the emergence of colistin resistance. A recent meta-analysis of in vitro data has confirmed this for A. baumannii. In that analysis, high in vitro synergy was shown with polymyxins in combination with carbapenems, rifampicin, and glycopeptides [57]. Carbapenem or rifampicin combinations also suppressed the development of colistin resistance and displayed a $>50 \%$ synergy rate against colistin-resistant strains. Interestingly, that study also found colistin/carbapenem and colistin/rifampicin combinations were more synergistic than polymyxin $\mathrm{B} /$ carbapenem and polymyxin $\mathrm{B} /$ rifampicin combinations. As in vitro data continue to accumulate, the ability to interpret and compare the results of future studies would benefit greatly from a more standardized approach to testing including uniform definitions (e.g., for synergy), breakpoints, and duration. 

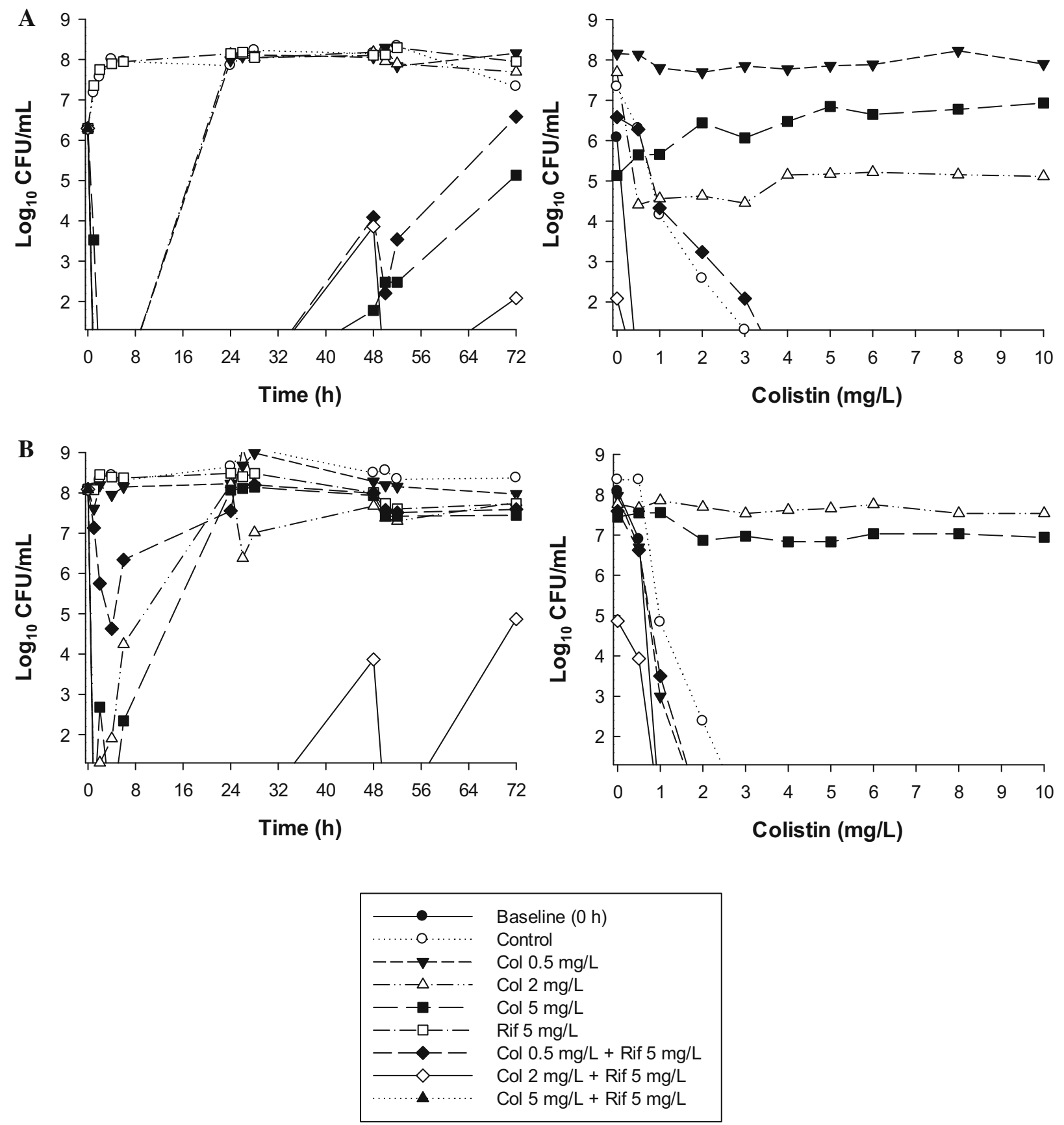

Fig. 3 Left Time-kill curves with various clinically relevant dosage regimens of colistin (Col) and rifampicin (Rif) alone and in combination at an inoculum of $\sim 10^{6} \mathrm{cfu} / \mathrm{mL}$ (a) and $\sim 10^{8} \mathrm{cfu} / \mathrm{mL}(\mathbf{b})$ against a MDR-colistin-susceptible clinical isolate of $A$. baumannii. Right Population analysis profiles (PAPs) at baseline $(0 \mathrm{~h})$ and after $72-\mathrm{h}$ exposure to colistin monotherapy, colistin/rifampicin combination therapy, or neither antibiotic (control). The $y$-axis starts from the limit of detection and the limit of quantification (LOQ) is indicated by the horizontal broken line. Figure adapted from Lee et al. [22], with permission 


\section{Animal Studies}

Few in vivo preclinical investigations into polymyxin combination therapy have been undertaken, with all existing studies utilizing CMS (the inactive prodrug of colistin [1]) or colistin [60, 69, 86, 95-97, 115-120]. Unfortunately, the results of these investigations are difficult to interpret due to significant shortcomings in study design and ambiguity in the form of 'colistin' administered (colistin sulfate or CMS). Administration of colistin sulfate is preferable to that of CMS as it permits greater control over the PK profile of the active species, colistin; in patients, colistin forms in vivo following administration of CMS $[7,9,111,112]$. Importantly, the doses of CMS/colistin employed appear to have been chosen to reflect human doses on a $\mathrm{mg} / \mathrm{kg}$ basis, ignoring the importance animal scaling that results in dissimilarities across species and likely resulting in substantially lower plasma concentrations in the animals compared with patients [121]. Further complications include the near complete absence of PK data, preventing comparisons with $\mathrm{PK}$ profiles achieved in patients, and the small number of isolates tested (many studies utilizing a single isolate). As a result of these significant shortcomings, animal studies are considered only briefly.

Using a reference strain of $P$. aeruginosa in a mouse pneumoniae model, Aoki et al. [60] observed that all control mice and mice treated with CMS [administered intranasally $(5 \mathrm{mg} / \mathrm{kg} / 12 \mathrm{~h}$ ) or subcutaneously (SC; $10 \mathrm{mg}$ / $\mathrm{kg} 12 \mathrm{~h}$ )], imipenem (30 mg/kg $12 \mathrm{~h} \mathrm{SC}$ ) or rifampicin $\quad(25 \mathrm{mg} / \mathrm{kg} / 24 \mathrm{~h} \quad$ orally $)$ monotherapy died within $42 \mathrm{~h}$ of infection. However, CMS plus imipenem or rifampicin increased survival to $62.5 \%$ and $75 \%$ at $72 \mathrm{~h}$, respectively, with a clear difference observed in survival between mice treated with intranasal or
SC CMS plus rifampicin $(100 \%$ vs. $14 \%$; $P<0.01)$; intranasal CMS was also superior to SC CMS when combined with imipenem. Similar improvements in survival were also observed with a colistin-susceptible MDR clinical isolate. Cirioni et al. examined 'colistin' (1 mg/kg; CMS or colistin sulfate not specified) in combination with either imipenem (mouse model; $20 \mathrm{mg} / \mathrm{kg}$ ) or rifampicin (rat model; $10 \mathrm{mg} / \mathrm{kg}$ ) against a reference strain and colistin-susceptible MDR clinical isolate of $P$. aeruginosa using mouse [69] and rat [118] sepsis models; each drug was administered IV as a single dose. 'Colistin' in combination with either drug resulted in substantially greater bacterial killing across $72 \mathrm{~h}$ than with monotherapy, although only one combination (colistin plus imipenem) significantly lowered mortality.

Several studies have examined CMS or colistin in combination with tigecycline [86, 95-97]. Using a single MDR colistin- and imipenem-susceptible strain of A. baumannii in a rat pneumonia model, Yilmaz et al. [97] found no difference in efficacy across $48 \mathrm{~h}$ between CMS (1.25 mg/kg/6 h intraperitoneally (IP)) and tigecycline $(10 \mathrm{mg} / \mathrm{kg} / 12 \mathrm{~h}$ IP) monotherapy and combination therapy. Against a single oxacillinase

(OXA)-48-producing carbapenem-resistant but colistin- and tigecycline-susceptible isolate of K. pneumoniae in a sepsis mouse model, Demiraslan et al. [95] found no difference in bacterial counts in liver and lung samples at 24 and $48 \mathrm{~h}$ between the most active monotherapy (CMS, $5 \mathrm{mg} / \mathrm{kg} / 12 \mathrm{~h}$ IP) and the combination of CMS plus tigecycline $(20 \mathrm{mg} / \mathrm{kg} / 12 \mathrm{~h} \quad$ IP $)$ in either immunocompetent or immunosuppressed mice. This same combination was similarly ineffective against K. pneumoniae in a murine thigh infection model [96]. Corvec et al. [86] examined colistin combinations against 
biofilms in vivo using a foreign-body infection model involving the implantation of Teflon cages into guinea pigs (four cages/guinea pig). Against a single extended-spectrum- $\beta$-lactamase (ESBL)-producing clinical strain of E. coli, colistin $(15 \mathrm{mg} / \mathrm{kg})$ was combined with either tigecycline $(10 \mathrm{mg} / \mathrm{kg})$, fosfomycin $(150 \mathrm{mg} / \mathrm{kg})$, or gentamicin $(10 \mathrm{mg} / \mathrm{kg})$, with antibiotics administered 12-hourly IP for 4 days; the strain employed was susceptible to all antibiotics tested. Five days after the cessation of treatment, only monotherapy with fosfomycin resulted in the eradication of some biofilms (cure rate of $17 \%$ ). However, cure rates were significantly increased to $50 \%, 67 \%$, and $33 \%$ with colistin combined with tigecycline, fosfomycin, and gentamicin, respectively.

Giacometti et al. [119] employed a rat IP infection model to examine 'colistin' ( $1 \mathrm{mg} / \mathrm{kg}$; CMS or colistin sulphate not specified) in combination with piperacillin $(60 \mathrm{mg} / \mathrm{kg})$ against a single reference strain of $E$. coli. Mortality at $48 \mathrm{~h}$ following a single IP administration of antibiotics was $93.3 \%$, $33.3 \%, 33.3 \%$, and $0 \%$ for controls, 'colistin' monotherapy, piperacillin monotherapy, and the combination, respectively. In a similar rat intraperitoneal model, CMS (IP; $5 \mathrm{mg} / \mathrm{kg} 12 \mathrm{~h}$ ) plus doripenem (IP; $150 \mathrm{mg} / \mathrm{kg} 12 \mathrm{~h}$ ) produced lower bacterial counts in both lung and liver at $48 \mathrm{~h}$ but no difference at $72 \mathrm{~h}$ when compared to monotherapy [120]. Against A. baumannii, studies combining CMS with rifampicin (mouse pneumonia model $[115,116]$ and rat thigh infection model [117]) or sulbactam (mouse sepsis model [122]), showed no difference in survival and/or bacterial clearance between mono- or combination therapy. However, in an Galleria mellonella infection model utilizing one reference strain and one colistin-susceptible MDR clinical isolate, colistin $(2.5 \mathrm{mg} / \mathrm{kg})$ combined with a glycopeptide (vancomycin or teicoplanin, $10 \mathrm{mg} / \mathrm{kg}$ ) [123] or telavancin (10 $\mathrm{mg} / \mathrm{kg}$ ) [124] significantly enhanced survival of MDR A. baumannii infected caterpillars over $96 \mathrm{~h}$ compared with equivalent monotherapy, despite the isolate being highly resistant to both glycopeptides. Similar improvements in survival have been demonstrated in the same model with colistin combined with tigecycline against a range of carbapenem-resistant Enterobacteriaceae [90], and the same combination plus a colistin/rifampicin combination against Stenotrophomonas maltophilia [68].

As outlined at the beginning of this section, there are significant shortcomings with the existing preclinical in vivo data. The limited available data do indicate a potential therapeutic benefit for some combinations, particularly colistin plus imipenem or rifampicin against $P$. aeruginosa, colistin plus piperacillin or doripenem against E. coli, and colistin plus a glycopeptide (but not colistin plus tigecycline) against $A$. baumannii. The existing data are limited, however, and firm conclusions cannot be made at this time. Well-designed animal studies which lack the major deficiencies that presently characterize existing investigations are clearly warranted. In particular, future studies should utilize colistin (or polymyxin B) and aim to simulate human PK profiles for each drug, reporting the concentrations achieved. Such studies will be crucial to more accurately assessing the true value of particular combinations and for optimization in patients. 


\section{CLINICAL STUDIES OF CMS OR POLYMYXIN B COMBINATION THERAPY}

While preclinical studies can provide preliminary guidance for rational drug combination use in the clinic, the true value of polymyxin combination therapy must ultimately be determined through well-designed clinical studies. Unfortunately, clinical data regarding CMS or polymyxin B therapy are generally limited to non-randomized, retrospective analysis and small, low-power, prospective trials. Studies also frequently pool patients with many types and sites of infection with varying degrees of severity, further limiting the power of the results obtained, and employ a variety of definitions for outcomes. The doses of antibiotics administered are often not stated, and PK data are usually absent. Importantly, the majority of existing studies where the doses administered are known utilize CMS dosed in a traditional manner (i.e. according to the product information); when administered in this way, patients typically receive around 6 million IU daily. The emerging PK data on CMS and formed colistin (the latter being the active entity [1]) indicate that such dosing is likely to lead to suboptimal colistin exposure and the emergence of polymyxin resistance [7-10, 111]. Recent studies have suggested the use of a loading dose of 9 million IU per day of CMS (equivalent to $\sim 270 \mathrm{mg}$ of CBA) followed by 9 million IU per day in divided doses in order to more rapidly attain higher plasma concentrations [112, 125, 126]; loading doses have similarly been suggested for polymyxin B $[8,127]$. Such a situation combined with the inherent practical and ethical considerations in undertaking such investigations (e.g., lack of appropriate controls) means that there are currently major limitations with published clinical studies. This section will outline results from recent clinical investigations; studies which included only very small patient numbers are not examined.

A small number of studies suggest polymyxin combinations may be of use in the treatment of infections caused by KPC-producing K. pneumoniae [128-130]. Qureshi et al. [128] retrospectively examined 41 unique patients with bacteremia caused by KPC-producing K. pneumoniae; of these, 32 (78\%) were hospital acquired with the remainder health care associated. Fifteen patients received monotherapy with most receiving CMS or polymyxin B $(n=7)$, tigecycline $\quad(n=5), \quad$ or $\quad$ a carbapenem (imipenem or meropenem; $n=4$ ); 15 patients received combination antibiotics. Unfortunately, the doses of antibiotics administered were not reported. For combination therapy, CMS or polymyxin B were combined with unspecified carbapenems $(n=5)$, tigecycline $(n=1)$ or a fluoroquinolone $(n=1)$ while the most common polymyxin-free combination was tigecycline with either a carbapenem $(n=3)$ or aminoglycoside $(n=2)$. The only significant predictor of survival was combination therapy [28-day mortality of $13.3 \%(2 / 15)$ compared to $57.8 \%(11 / 19)$ for monotherapy], with only 1 (14\%) of 7 of patients receiving polymyxin combination therapy dying compared to $4(57.1 \%)$ of 7 patients that received polymyxin monotherapy. This latter value is higher than a previous study examining polymyxin $\mathrm{B}$ monotherapy against KPC-producing K. pneumoniae [131] and may be due to the greater severity of illness in these mostly critically ill patients. A case-control study conducted in Greece which examined KPC-producing K.pneumoniae bloodstream 
infections produced similar results [129]. In that study, none of 20 patients receiving multiple antibiotics died (doses not specified; 14 patients received CMS in combination, primarily with tigecycline) compared to $7(46.7 \%)$ of 15 patients receiving monotherapy. Of this latter group, 7 received CMS as monotherapy with 4 (66.7\%) dying.

In 23 critically ill patients with a variety of infection types (some with multiple infections) including pneumonia $(n=18)$, bacteremia $(n=8)$ and intra-abdominal infections $(n=6)$ caused by MDR $P$. aeruginosa, Linden et al. [132] prospectively compared treatment with CMS mono- $(n=10)$ and combination $(n=13)$ therapy. CMS was administered IV based on ideal body weight and estimated creatinine clearance $\quad\left(\mathrm{Cr}_{\mathrm{CL}} \sim 2.7-13.3 \mathrm{mg} / \mathrm{kg} / \mathrm{day}\right.$, equivalent to $\sim 33,000-167,000 \mathrm{IU} / \mathrm{kg} /$ day). For the combination group, CMS was administered with amikacin or an antipseudomonal $\beta$-lactam. An unfavorable response, defined as persistence or worsening of presenting signs and symptoms or death, was reported for 4 (40\%) of 10 of patients receiving only CMS and $5(38.5 \%)$ of 13 of patients on combination therapy. In a similar study by Furtado et al. [133] in which polymyxin B (dosed according to $\mathrm{Cr}_{\mathrm{CL}}$; e.g. patients with a $\mathrm{Cr}_{\mathrm{CL}} \geq 80 \mathrm{~mL} / \mathrm{min}$ received $1.5-2.5 \mathrm{mg} / \mathrm{kg} /$ day) was administered as a continuous infusion over $24 \mathrm{~h}$, polymyxin B combinations $[n=28$; most commonly combined with imipenem $(n=24)]$ were not found to provide additional benefit over polymyxin B monotherapy $(n=46)$ for the treatment of nosocomial pneumonia caused by polymyxin-susceptible MDR $P$. aeruginosa.

As for $P$. aeruginosa discussed above, existing evidence from clinical studies does not provide support for the use of polymyxin-based combinations in the treatment of infections caused by MDR A. baumannii. Aydemir et al.
[43] prospectively investigated 43 patients with ventilator-associated pneumonia (VAP) caused by carbapenem-resistant $A$. baumannii. Patients were randomized to receive CMS monotherapy [300 mg CBA per day (equivalent to $\sim 10$ million IU/day) IV in three divided doses, adjusted for renal impairment] or CMS (same dose) plus rifampicin (600 mg/day nasogastrically). Although time to microbiological clearance was significantly shorter in the group of patients that received combination therapy $(3.1 \pm 0.5$ vs. $4.5 \pm 1.7$ days), there was no significant difference in clinical response between the groups. Similarly, a retrospective study by Yilmaz et al. [50] found no significant differences in clinical and microbiological efficacy and mortality between a group of 70 patients receiving treatment for VAP caused by MDR or XDR A. baumannii who received CMS alone $(n=17)$, CMS plus sulbactam $(n=20)$, or CMS plus a carbapenem $(n=33)$; the daily dose of CMS administered was $\sim 7.5$ or 10 million IU/day. In a larger multi-center prospective study involving 209 patients with various infections caused by XDR A. baumannii (XDR defined as an MIC $\geq 16 \mathrm{mg} / \mathrm{L}$ for carbapenems and resistant to all other antibiotics except colistin), Durante-Mangoni et al. [41] allocated patients to receive either CMS (160 mg or 2 million IU IV 8-hourly) alone or in combination with rifampicin (600 mg IV 12-hourly); there were 104 and 105 patients in each group, respectively. The majority of patients (69.8\%) had VAP, while the remaining had bloodstream infections (20.1\%), hospital acquired pneumonia $(8.6 \%)$, or intra-abdominal infections $(2.4 \%)$. For the primary endpoint of 30-day mortality, there was no significant difference between the two groups; however, eradication of $A$. baumannii was significantly higher with the addition of rifampicin (60.6 vs. $44.8 \%)$. In an open-label randomized controlled 
study examining CMS [5 mg CBA/kg/day IV ( 167,000 IU/kg/day)] plus fosfomycin (4 g IV $12 \mathrm{~h}$ ) for 7-14 days vs. the equivalent CMS monotherapy ( $n=47$ for both groups) for treatment of carbapenem-resistant A. baumannii, no difference in 28-day mortality between the groups was observed $(46.8 \%$ vs. $57.4 \%$ [46]. However, microbiological eradication was significantly higher than with monotherapy $(90.7 \%$ vs. $58.1 \%$ at $72 \mathrm{~h}$, and $100 \%$ vs. $81.2 \%$, respectively, at the end of study treatment). Interestingly, although it has been suggested that fosfomycin may potentially attenuate polymyxin nephrotoxicity [45], no differences in acute kidney injury were observed $(53.4 \%$ vs. $59.6 \%$ for combination and monotherapy groups, respectively).

Finally, based on the potent and maintained synergism observed in preclinical models against $A$. baumannii with colistin plus a glycopeptide (see preclinical investigations) [87, 88, 123], two groups recently retrospectively examined the efficacy and safety of such combinations in critically ill patients with Gram-negative bacterial infections [38, 39]. The smaller of the two studies included only critically ill patients with serious infections (VAP or bacteraemia) caused by carbapenem-resistant A baumannii [38]. Administration of vancomycin was for coinfection with a Gram-positive organism. No significant differences were observed in clinical cure, microbiological eradication or 28-day mortality between patients receiving CMS with $(n=29$; mean daily dose of $6.5 \pm 1.63$ million IU) or without $(n=28$; mean daily dose of $7.0 \pm 3.62$ million IU) vancomycin $(2 \mathrm{~g} /$ day via 60 -min infusion in patients with normal renal function). However, the rate of acute kidney injury was significantly higher in the group receiving vancomycin $(55.2 \%$ vs. $28.6 \%)$. Similarly, in a larger study examining CMS/ glycopeptide (vancomycin or teicoplanin) combinations in critically ill patients with Gram-negative bacterial infections (primarily MDR A. baumannii) 30-day mortality was not significantly different between those treated with the combination $(n=68)$ and those treated with monotherapy $(n=61 ; 33.8 \%$ vs. 29.6\%) [39]. However, Cox regression did show treatment with the combination for at least 5 days was a factor independently associated with better outcomes among all patients. In contrast to the smaller study, the rate of nephrotoxicity was low $(\leq 8 \%)$ with no differences between the groups.

As can be readily seen from the currently published clinical studies, an enhanced therapeutic effect with polymyxin combinations suggested by many in vitro studies, especially those undertaken in dynamic models, has so far not been observed in clinical studies. However, as previously highlighted polymyxin dosage regimens administered clinically have not been optimized, this means that the existing data are based on suboptimal usage. In order to determine the true therapeutic potential of polymyxin combinations and optimize their effectiveness, both the choice of the second antibiotic and the dosage regimens of the polymyxin and the second antibiotic in the combination need to be optimized. Such optimization should be based upon the emerging PK data and PK/PD principles and utilize well-designed pre-clinical studies and translational mathematical modeling. Promising dosage regimens include the use of a loading dose to more rapidly attain effective plasma concentrations. Until clinical effectiveness studies with optimized regimens are forthcoming, the true therapeutic benefit of polymyxins, whether administered as monotherapy or in combination, will remain uncertain. 


\section{CONCLUSION}

The available in vitro data for polymyxin combination therapy suggest a potential clinical benefit with many drug combinations, particularly when only data from the more sophisticated dynamic models are considered. Substantial improvements in bacterial killing even of isolates resistant to one or more drugs in combination have been observed with polymyxin combination therapy at low (clinically achievable) concentrations. Importantly, in an era of increasing emergence of polymyxin resistance, combination therapy has been shown to substantially reduce the emergence of polymyxin-resistant subpopulations. Nevertheless, despite the numerous successes reported with polymyxin combinations in vitro it is difficult to make a case for therapeutic benefits from the use of polymyxin combination therapy based on existing clinical data. The use of higher dose polymyxin regimens, especially in combination, requires further investigation in patients in order to fully define their therapeutic role, particularly for infections with MDR Gram-negative organisms such as $P$. aeruginosa, A. baumannii and $K$. pneumoniae where mortality rates remain high. Clearly further multi-center, randomized trials using uniform protocols are urgently required to more adequately understand the benefits or otherwise of polymyxin combination therapy.

\section{ACKNOWLEDGMENTS}

Research reported in this publication was supported in part by National Institute of Allergy and Infectious Diseases of the National Institutes of Health under award number R01AI111990. The content is solely the responsibility of the authors and does not necessarily represent the official views of the National Institutes of Health. C.B.L. is the recipient of an NHMRC Career Development fellowship (APP1062509). All named authors meet the International Committee of Medical Journal Editors (ICMJE) criteria for authorship for this manuscript, take responsibility for the integrity of the work as a whole, and have given final approval to the version to be published. This article is based on previously conducted studies and does not involve any new studies of human or animal subjects performed by any of the authors.

Disclosures. Phillip J. Bergen, Zackery P. Bulman, Cornelia B. Landersdorfer, Nicholas Smith, Justin R. Lenhard, Juergen B. Bulitta, Roger L. Nation, Jian Li, Brian T. Tsuji have nothing to disclose.

Compliance with ethics guidelines. This article is based on previously conducted studies and does not involve any new studies of human or animal subjects performed by any of the authors.

Open Access. This article is distributed under the terms of the Creative Commons Attribution-NonCommercial 4.0 International License (http://creativecommons.org/licenses/ by-nc/4.0/), which permits any noncommercial use, distribution, and reproduction in any medium, provided you give appropriate credit to the original author(s) and the source, provide a link to the Creative Commons license, and indicate if changes were made.

\section{REFERENCES}

1. Bergen PJ, Li J, Rayner CR, Nation RL. Colistin methanesulfonate is an inactive prodrug of colistin against Pseudomonas aeruginosa. Antimicrob Agents Chemother. 2006;50(6): 1953-8. 
2. Koch-Weser J, Sidel VW, Federman EB, Kanarek P, Finer DC, Eaton AE. Adverse effects of sodium colistimethate. Manifestations and specific reaction rates during 317 courses of therapy. Ann Intern Med. 1970;72(6):857-68.

3. Yow EM, Moyer JH. Toxicity of polymyxin B. II. Human studies with particular reference to evaluation of renal function. AMA Arch Intern Med. 1953;92(2):248-57.

4. WHO. Antimicrobial resistance: global report on surveillance. 2014 April 2014. Report No. http:// www.who.int/drugresistance/documents/surveill ancereport/en/. Accessed 25 July 2015.

5. Walker B, Barrett S, Polasky S, Galaz V, Folke C, Engstrom $G$, et al. Environment. Looming global-scale failures and missing institutions. Science. 2009;325(5946):1345-6.

6. Boucher HW, Talbot GH, Benjamin DK Jr, Bradley J, Guidos RJ, Jones RN, et al. 10 × '20 Progressdevelopment of new drugs active against gram-negative bacilli: an update from the Infectious Diseases Society of America. Clin Infect Dis. 2013;56(12):1685-94.

7. Garonzik SM, Li J, Thamlikitkul V, Paterson DL, Shoham S, Jacob J, et al. Population pharmacokinetics of colistin methanesulfonate and formed colistin in critically ill patients from a multicenter study provide dosing suggestions for various categories of patients. Antimicrob Agents Chemother. 2011;55(7):3284-94 (Epub 2011/05/ 11. eng).

8. Sandri AM, Landersdorfer CB, Jacob J, Boniatti MM, Dalarosa MG, Falci DR, et al. Population pharmacokinetics of intravenous polymyxin $\mathrm{B}$ in critically ill patients: implications for selection of dosage regimens. Clin Infect Dis. 2013;57(4):524-31.

9. Mohamed AF, Karaiskos I, Plachouras D, Karvanen M, Pontikis K, Jansson B, et al. Application of a loading dose of colistin methanesulfonate in critically ill patients: population pharmacokinetics, protein binding, and prediction of bacterial kill. Antimicrob Agents Chemother. 2012;56(8):4241-9 (Epub 2012/05/23. eng).

10. Li J, Coulthard K, Milne R, Nation RL, Conway S, Peckham D, et al. Steady-state pharmacokinetics of intravenous colistin methanesulphonate in patients with cystic fibrosis. J Antimicrob Chemother. 2003;52(6):987-92.

11. Bergen PJ, Bulitta JB, Forrest A, Tsuji BT, Li J, Nation RL. Pharmacokinetic/pharmacodynamic investigation of colistin against Pseudomonas aeruginosa using an in vitro model. Antimicrob Agents Chemother. 2010;54(9):3783-9 (Epub 2010/06/30. eng).

12. Gunderson BW, Ibrahim KH, Hovde LB, Fromm TL, Reed MD, Rotschafer JC. Synergistic activity of colistin and ceftazidime against multiantibiotic-resistant Pseudomonas aeruginosa in an in vitro pharmacodynamic model. Antimicrob Agents Chemother. 2003;47(3): 905-9.

13. Owen RJ, Li J, Nation RL, Spelman D. In vitro pharmacodynamics of colistin against Acinetobacter baumannii clinical isolates. J Antimicrob Chemother. 2007;59(3):473-7 (Epub 2007/02/10. eng).

14. Poudyal A, Howden BP, Bell JM, Gao W, Owen RJ, Turnidge JD, et al. In vitro pharmacodynamics of colistin against multidrug-resistant Klebsiella pneumoniae. J Antimicrob Chemother. 2008;62(6):1311-8 (Epub 2008/10/17. eng).

15. Tam VH, Schilling AN, Vo G, Kabbara S, Kwa AL, Wiederhold NP, et al. Pharmacodynamics of polymyxin B against Pseudomonas aeruginosa. Antimicrob Agents Chemother. 2005;49(9): 3624-30.

16. Tan $\mathrm{CH}, \mathrm{Li}$ J, Nation RL. Activity of colistin against heteroresistant Acinetobacter baumannii and emergence of resistance in an in vitro pharmacokinetic/pharmacodynamic model. Antimicrob Agents Chemother. 2007;51(9):34135 (Epub 2007/07/11. eng).

17. Bergen PJ, Forrest A, Bulitta JB, Tsuji BT, Sidjabat HE, Paterson DL, et al. Clinically relevant plasma concentrations of colistin in combination with imipenem enhance pharmacodynamic activity against multidrug-resistant Pseudomonas aeruginosa at multiple inocula. Antimicrob Agents Chemother. 2011;55(11):5134-42 (Epub 2011/08/31. eng).

18. Bergen PJ, Tsuji BT, Bulitta JB, Forrest A, Jacob J, Sidjabat $\mathrm{HE}$, et al. Synergistic killing of multidrug-resistant Pseudomonas aeruginosa at multiple inocula by colistin combined with doripenem in an in vitro pharmacokinetic/ pharmacodynamic model. Antimicrob Agents Chemother. 2011;55(12):5685-95 (Epub 2011/09/14. eng).

19. Bulitta JB, Yang JC, Yohonn L, Ly NS, Brown SV, $\mathrm{D}^{\prime}$ Hondt RE, et al. Attenuation of colistin bactericidal activity by high inoculum of Pseudomonas aeruginosa characterized by a new mechanism-based population pharmacodynamic model. Antimicrob Agents Chemother. 2010;54(5):2051-62 (Epub 2010/03/10. eng). 
20. Bergen PJ, Li J, Nation RL, Turnidge JD, Coulthard $\mathrm{K}$, Milne RW. Comparison of once-, twice- and thrice-daily dosing of colistin on antibacterial effect and emergence of resistance: studies with Pseudomonas aeruginosa in an in vitro pharmacodynamic model. J Antimicrob Chemother. 2008;61(3):636-42.

21. Deris ZZ, Yu HH, Davis K, Soon RL, Jacob J, Ku CK, et al. The combination of colistin and doripenem is synergistic against Klebsiella pneumoniae at multiple inocula and suppresses colistin resistance in an in vitro pharmacokinetic/ pharmacodynamic model. Antimicrob Agents Chemother. 2012;56(10):5103-12 (Epub 2012/07/18. eng).

22. Lee HJ, Bergen PJ, Bulitta JB, Tsuji B, Forrest A, Nation RL, et al. Synergistic activity of colistin and rifampin combination against multidrug-resistant Acinetobacter baumannii in an in vitro pharmacokinetic/pharmacodynamic model. Antimicrob Agents Chemother. 2013;57(8): 3738-45.

23. Ly NS, Bulitta JB, Rao GG, Landersdorfer CB, Holden PN, Forrest A, et al. Colistin and doripenem combinations against Pseudomonas aeruginosa: profiling the time course of synergistic killing and prevention of resistance. J Antimicrob Chemother. 2015;70(5):1434-42 (Epub 2015/02/ 26. eng).

24. Abdul Rahim N, Cheah SE, Johnson MD, Yu H, Sidjabat HE, Boyce J, et al. Synergistic killing of NDM-producing MDR Klebsiella pneumoniae by two 'old' antibiotics-polymyxin B and chloramphenicol. J Antimicrob Chemother. 2015;70(9):2589-97.

25. Choi MJ, Ko KS. Mutant prevention concentrations of colistin for Acinetobacter baumannii, Pseudomonas aeruginosa and Klebsiella pneumoniae clinical isolates. J Antimicrob Chemother. 2014;69(1):275-7.

26. Lister PD, Wolter DJ, Hanson ND. Antibacterial-resistant Pseudomonas aeruginosa: clinical impact and complex regulation of chromosomally encoded resistance mechanisms. Clin Microbiol Rev. 2009;22(4):582-610 (Epub 2009/10/14. eng).

27. Rahal JJ. Novel antibiotic combinations against infections with almost completely resistant Pseudomonas aeruginosa and Acinetobacter species. Clin Infect Dis. 2006;1(43 Suppl 2):S95-9 (Epub 2006/08/09. eng).

28. Herrmann G, Yang L, Wu H, Song Z, Wang H, Hoiby $\mathrm{N}$, et al. Colistin-tobramycin combinations are superior to monotherapy concerning the killing of biofilm Pseudomonas aeruginosa. J Infect Dis. 2010;202(10):1585-92 (Epub 2010/10/15. eng).

29. Bulitta JB, Li J, Poudyal A, Yu HH, Owen RJ, Tsuji BT, et al. Quantifying synergy of colistin combinations against MDR Gram-negatives by mechanism-based models (abstract A1-573, p41). In: Abstracts of the 49th Annual Interscience Conference of Antimicrobial Agents and Chemotherapy (ICAAC), San Francisco: American Society for Microbiology, September 12-15; 2009.

30. Gales AC, Jones RN, Sader HS. Contemporary activity of colistin and polymyxin $\mathrm{B}$ against a worldwide collection of Gram-negative pathogens: results from the SENTRY Antimicrobial Surveillance Program (2006-09). J Antimicrob Chemother. 2011;66(9):2070-4 (Epub 2011/07/ 01. eng).

31. Al-Sweih NA, Al-Hubail MA, Rotimi VO. Emergence of tigecycline and colistin resistance in acinetobacter species isolated from patients in Kuwait hospitals. J Chemother. 2011;23(1):13-6 (Epub 2011/04/13. eng).

32. Bogdanovich T, Adams-Haduch JM, Tian GB, Nguyen MH, Kwak EJ, Muto CA, et al. Colistin-resistant, Klebsiella pneumoniae carbapenemase (KPC)-producing Klebsiella pneumoniae belonging to the international epidemic clone ST258. Clin Infect Dis. 2011;53(4):373-6 (Epub 2011/08/04. eng).

33. Lee JY, Song JH, Ko KS. Identification of nonclonal Pseudomonas aeruginosa isolates with reduced colistin susceptibility in Korea. Microb Drug Resist. 2011;17(2):299-304 (Epub 2011/03/09. eng).

34. Marchaim D, Chopra T, Pogue JM, Perez F, Hujer $\mathrm{AM}$, Rudin S, et al. Outbreak of colistin-resistant, carbapenem-resistant Klebsiella pneumoniae in metropolitan Detroit, Michigan. Antimicrob Agents Chemother. 2011;55(2):593-9 (Epub 2010/12/01. eng).

35. Petrosillo N, Ioannidou E, Falagas ME. Colistin monotherapy vs. combination therapy: evidence from microbiological, animal and clinical studies. Clin Microbiol Infect. 2008;14(9):816-27 (Epub 2008/10/11. eng).

36. Kasiakou SK, Michalopoulos A, Soteriades ES, Samonis G, Sermaides GJ, Falagas ME. Combination therapy with intravenous colistin for management of infections due to multidrug-resistant Gram-negative bacteria in patients without cystic fibrosis. Antimicrob Agents Chemother. 2005;49(8):3136-46. 
37. Shields RK, Clancy CJ, Gillis LM, Kwak EJ, Silveira FP, Massih RC, et al. Epidemiology, clinical characteristics and outcomes of extensively drug-resistant Acinetobacter baumannii infections among solid organ transplant recipients. PLoS ONE. 2012;7(12):e52349.

38. Garnacho-Montero J, Amaya-Villar R, Gutierrez-Pizarraya A, Espejo-Gutierrez de Tena E, Artero-Gonzalez ML, Corcia-Palomo Y, et al. Clinical efficacy and safety of the combination of colistin plus vancomycin for the treatment of severe infections caused by carbapenem-resistant Acinetobacter baumannii. Chemotherapy. 2013;59(3):225-31.

39. Petrosillo N, Giannella M, Antonelli M, Antonini M, Barsic B, Belancic L, et al. Clinical experience of colistin-glycopeptide combination in critically ill patients infected with Gram-negative bacteria. Antimicrob Agents Chemother. 2014;58(2): 851-8.

40. Morelli P, Ferrario A, Tordato F, Piazza A, Casari E. Successful treatment of post-neurosurgical multidrug-resistant Pseudomonas aeruginosa meningo-encephalitis with combination therapy of colistin, rifampicin and doripenem. J Antimicrob Chemother. 2014;69(3):857-9.

41. Durante-Mangoni E, Signoriello G, Andini R, Mattei A, De Cristoforo M, Murino P, et al. Colistin and rifampicin compared with colistin alone for the treatment of serious infections due to extensively drug-resistant Acinetobacter baumannii: a multicenter, randomized clinical trial. Clin Infect Dis. 2013;57(3):349-58.

42. Ceccarelli G, Falcone M, Giordano A, Mezzatesta ML, Caio C, Stefani S, et al. Successful ertapenem-doripenem combination treatment of bacteremic ventilator-associated pneumonia due to colistin-resistant KPC-producing Klebsiella pneumoniae. Antimicrob Agents Chemother. 2013;57(6):2900-1.

43. Aydemir H, Akduman D, Piskin N, Comert F, Horuz E, Terzi A, et al. Colistin vs. the combination of colistin and rifampicin for the treatment of carbapenem-resistant Acinetobacter baumannii ventilator-associated pneumonia. Epidemiol Infect. 2013;141(6):1214-22 (Epub 2012/09/08. eng).

44. Batirel A, Balkan, II, Karabay O, Agalar C, Akalin S, Alici $\mathrm{O}$, et al. Comparison of colistin-carbapenem, colistin-sulbactam, and colistin plus other antibacterial agents for the treatment of extremely drug-resistant Acinetobacter baumannii bloodstream infections. Eur J Clin Microbiol Infect Dis. 2014;33(8):1311-22.
45. Pontikis K, Karaiskos I, Bastani S, Dimopoulos G, Kalogirou M, Katsiari M, et al. Outcomes of critically ill intensive care unit patients treated with fosfomycin for infections due to pandrug-resistant and extensively drug-resistant carbapenemase-producing Gram-negative bacteria. Int J Antimicrob Agents. 2014;43(1): 52-9.

46. Sirijatuphat R, Thamlikitkul V. Preliminary study of colistin versus colistin plus fosfomycin for treatment of carbapenem-resistant Acinetobacter baumannii infections. Antimicrob Agents Chemother. 2014;58(9):5598-601 (Epub 2014/07/02. eng).

47. Chua NG, Zhou YP, Tan TT, Lingegowda PB, Lee W, Lim TP, et al. Polymyxin B with dual carbapenem combination therapy against carbapenemase-producing Klebsiella pneumoniae. J Infect. 2015;70(3):309-11 (Epub 2014/10/12. eng).

48. Dan JM, Mendler MH, Hemming AW, Aslam S. High-dose tigecycline and colistin for successful treatment of disseminated carbapenem-resistant Klebsiella pneumoniae infection in a liver transplant recipient. BMJ Case Rep. 2014.

49. Cheng A, Chuang YC, Sun HY, Sheng WH, Yang $\mathrm{CJ}$, Liao $\mathrm{CH}$, et al. Excess mortality associated with colistin-tigecycline compared with colistin-carbapenem combination therapy for extensively drug-resistant Acinetobacter baumannii bacteremia: a multicenter prospective observational study. Crit Care Med. 2015;43(6):1194-204 (Epub 2015/03/21. eng).

50. Yilmaz GR, Guven T, Guner R, Kocak Tufan Z, Izdes $\mathrm{S}$, Tasyaran MA, et al. Colistin alone or combined with sulbactam or carbapenem against A. baumannii in ventilator-associated pneumonia. J Infect Dev Ctries. 2015;9(5):476-85 (Epub 2015/05/20. eng).

51. Bergen PJ, Landersdorfer CB, Zhang J, Zhao M, Lee $\mathrm{HJ}$, Nation RL, et al. Pharmacokinetics and pharmacodynamics of 'old' polymyxins: what is new? Diagn Microbiol Infect Dis. 2012;74(3):213-23 (Epub 2012/09/11. eng).

52. Bergen PJ, Li J, Nation RL. Dosing of colistin-back to basic PK/PD. Curr Opin Pharmacol. 2011;11(5):464-9 (Epub 2011/08/13. eng).

53. Cappelletty DM, Rybak MJ. Comparison of methodologies for synergism testing of drug combinations against resistant strains of Pseudomonas aeruginosa. Antimicrob Agents Chemother. 1996;40(3):677-83 (Epub 1996/03/ 01. eng). 
54. Wootton M, Hedges AJ, Bowker KE, Holt HA, Reeves DS, MacGowan AP. A critical assessment of the agar dilution chequerboard technique for studying in vitro antimicrobial interactions using a representative beta-lactam, aminoglycoside and fluoroquinolone. J Antimicrob Chemother. 1995;35(5):569-76.

55. Norden CW, Wentzel H, Keleti E. Comparison of techniques for measurement of in vitro antibiotic synergism. J Infect Dis. 1979;140(4):629-33 (Epub 1979/10/01. eng).

56. Tan TY, Ng LS, Tan E, Huang G. In vitro effect of minocycline and colistin combinations on imipenem-resistant Acinetobacter baumannii clinical isolates. J Antimicrob Chemother. 2007;60(2):421-3 (Epub 2007/06/02. eng).

57. Ni W, Shao X, Di X, Cui J, Wang R, Liu Y. In vitro synergy of polymyxins with other antibiotics for Acinetobacter baumannii: a systematic review and meta-analysis. Int J Antimicrob Agents. 2015;45(1):8-18 (Epub 2014/12/04. eng).

58. Pillai SK, Moellering RC, Eliopoulos GM. Antimicrobial combinations. In: Lorian V, editor. Antibiotics in laboratory medicine. 5th ed. Philadelphia: Lippincott Williams \& Wilkins; 2005.

59. Zusman O, Avni T, Leibovici L, Adler A, Friberg L, Stergiopoulou $\mathrm{T}$, et al. Systematic review and meta-analysis of in vitro synergy of polymyxins and carbapenems. Antimicrob Agents Chemother. 2013;57(10):5104-11.

60. Aoki N, Tateda K, Kikuchi Y, Kimura S, Miyazaki C, Ishii $\mathrm{Y}$, et al. Efficacy of colistin combination therapy in a mouse model of pneumonia caused by multidrug-resistant Pseudomonas aeruginosa. J Antimicrob Chemother. 2009;63(3):534-42 (Epub 2009/01/17. Eng).

61. Tripodi MF, Durante-Mangoni E, Fortunato R, Utili $\mathrm{R}$, Zarrilli R. Comparative activities of colistin, rifampicin, imipenem and sulbactam/ampicillin alone or in combination against epidemic multidrug-resistant Acinetobacter baumannii isolates producing OXA-58 carbapenemases. Int J Antimicrob Agents. 2007;30(6):537-40 (Epub 2007/09/14. eng).

62. Liang W, Liu XF, Huang J, Zhu DM, Li J, Zhang J. Activities of colistin- and minocycline-based combinations against extensive drug resistant Acinetobacter baumannii isolates from intensive care unit patients. BMC Infect Dis. 2011;11:109 (Epub 2011/04/28. eng).
63. Tascini C, Gemignani G, Ferranti S, Tagliaferri E, Leonildi A, Lucarini A, et al. Microbiological activity and clinical efficacy of a colistin and rifampin combination in multidrug-resistant Pseudomonas aeruginosa infections. J Chemother. 2004;16(3): 282-7.

64. Attridge RT, Carden MF, Padilla S, Nathisuwan S, Burgess DS. Colistin and rifampicin alone and in combination against multidrug-resistant Acinetobacter baumannii using an in vitro PK-PD model (abstract C1-1053, p69). In: Abstracts of the 48th Annual Interscience Conference on Antimicrobial Agents and Chemotherapy (ICAAC), Washington, DC: American Society for Microbiology, October 25-28; 2008.

65. Nastro M, Rodriguez CH, Monge R, Zintgraff J, Neira L, Rebollo M, et al. Activity of the colistin-rifampicin combination against colistin-resistant, carbapenemase producing Gram-negative bacteria. J Chemother. 2014;26(4):211-6.

66. Tangden T, Hickman RA, Forsberg P, Lagerback P, Giske CG, Cars O. Evaluation of double- and triple-antibiotic combinations for VIM- and NDM-producing Klebsiella pneumoniae by in vitro time-kill experiments. Antimicrob Agents Chemother. 2014;58(3):1757-62.

67. Gaibani P, Lombardo D, Lewis RE, Mercuri M, Bonora S, Landini MP, et al. In vitro activity and post-antibiotic effects of colistin in combination with other antimicrobials against colistin-resistant KPC-producing Klebsiella pneumoniae bloodstream isolates. J Antimicrob Chemother. 2014;69(7): 1856-65.

68. Betts JW, Phee LM, Woodford N, Wareham DW. Activity of colistin in combination with tigecycline or rifampicin against multidrug-resistant Stenotrophomonas maltophilia. Eur J Clin Microbiol Infect Dis. 2014;33(9): $1565-72$.

69. Cirioni O, Ghiselli R, Silvestri C, Kamysz W, Orlando F, Mocchegiani F, et al. Efficacy of tachyplesin III, colistin, and imipenem against a multiresistant Pseudomonas aeruginosa strain. Antimicrob Agents Chemother. 2007;51(6): 2005-10.

70. Lin $\mathrm{KH}$, Chuang $\mathrm{YC}$, Lee $\mathrm{SH}, \mathrm{Yu}$ WL. In vitro synergistic antimicrobial effect of imipenem and colistin against an isolate of multidrug-resistant Enterobacter cloacae. J Microbiol Immunol Infect. 2010;43(4):317-22 (Epub 2010/08/07. eng).

71. Pankuch GA, Lin G, Seifert H, Appelbaum PC. Activity of meropenem with and without 
ciprofloxacin and colistin against Pseudomonas aeruginosa and Acinetobacter baumannii. Antimicrob Agents Chemother. 2008;52(1):333-6.

72. Pankuch GA, Seifert H, Appelbaum PC. Activity of doripenem with and without levofloxacin, amikacin, and colistin against Pseudomonas aeruginosa and Acinetobacter baumannii. Diagn Microbiol Infect Dis. 2010;67(2):191-7 (Epub 2010/03/27. eng).

73. Sheng WH, Wang JT, Li SY, Lin YC, Cheng A, Chen YC, et al. Comparative in vitro antimicrobial susceptibilities and synergistic activities of antimicrobial combinations against carbapenem-resistant Acinetobacter species: Acinetobacter baumannii versus Acinetobacter genospecies 3 and 13TU. Diagn Microbiol Infect Dis. 2011;70(3):380-6 (Epub 2011/05/12. eng).

74. Souli M, Rekatsina PD, Chryssouli Z, Galani I, Giamarellou H, Kanellakopoulou K. Does the activity of the combination of imipenem and colistin in vitro exceed the problem of resistance in metallo-beta-lactamase-producing Klebsiella pneumoniae isolates? Antimicrob Agents Chemother. 2009;53(5):2133-5 (Epub 2009/03/ 05. eng).

75. Urban C, Mariano N, Rahal JJ. In vitro double and triple bactericidal activities of doripenem, polymyxin B, and rifampin against Multidrug-resistant Acinetobacter baumannii, Pseudomonas aeruginosa, Klebsiella pneumoniae, and Escherichia coli. Antimicrob Agents Chemother. 2010;54(6):2732-4 (Epub 2010/04/ 07. eng).

76. Srisupha-olarn W, Burgess DS. Activity of meropenem and colistin alone and in combination against multidrug-resistant Acinetobacter baumannii in a pharmacokinetic-pharmacodynamic model (abstract E-1591, p125). In: Abstracts of the 50th Annual Interscience Conference on Antimicrobial Agents and Chemotherapy (ICAAC). Boston: American Society for Microbiology, September 12-15; 2010.

77. Lee GC, Burgess DS. Polymyxins and doripenem combination against KPC-producing Klebsiella pneumoniae. J Clin Med Res. 2013;5(2):97-100.

78. Principe L, Capone A, Mazzarelli A, D'Arezzo S, Bordi E, Di Caro A, et al. In vitro activity of doripenem in combination with various antimicrobials against multidrug-resistant Acinetobacter baumannii: possible options for the treatment of complicated infection. Microb Drug Resist. 2013;19(5):407-14.

79. Oleksiuk LM, Nguyen MH, Press EG, Updike CL, O'Hara JA, Doi Y, et al. In vitro responses of
Acinetobacter baumannii to two- and three-drug combinations following exposure to colistin and doripenem. Antimicrob Agents Chemother. 2014;58(2):1195-9.

80. Clancy CJ, Chen L, Hong JH, Cheng S, Hao B, Shields RK, et al. Mutations of the ompK36 porin gene and promoter impact responses of sequence type 258, KPC-2-producing Klebsiella pneumoniae strains to doripenem and doripenem-colistin. Antimicrob Agents Chemother. 2013;57(11): 5258-65.

81. Lora-Tamayo J, Murillo O, Bergen PJ, Nation RL, Poudyal A, Luo X, et al. Activity of colistin combined with doripenem at clinically relevant concentrations against multidrug-resistant Pseudomonas aeruginosa in an in vitro dynamic biofilm model. J Antimicrob Chemother. 2014;69(9):2434-42.

82. Tang $\mathrm{HJ}, \mathrm{Ku} \mathrm{YH}$, Lee MF. In vitro activity of imipenem and colistin against a carbapenem-resistant Klebsiella pneumoniae isolate coproducing SHV-31, CMY-2, and DHA-1. 2015;2015:568079. Biomed Res Int. 2015; 2015, Article ID 568079.

83. Hong JH, Clancy CJ, Cheng S, Shields RK, Chen L, Doi Y, et al. Characterization of porin expression in Klebsiella pneumoniae carbapenemase (KPC)-producing K. pneumoniae identifies isolates most susceptible to the combination of colistin and carbapenems. Antimicrob Agents Chemother. 2013;57(5):2147-53 (Epub 2013/03/06. eng).

84. Sun HY, Shields RK, Cacciarelli TV, Muder RR, Singh N. A novel combination regimen for the treatment of refractory bacteremia due to multidrug-resistant Pseudomonas aeruginosa in a liver transplant recipient. Transpl Infect Dis. 2010;12(6):555-60 (Epub 2010/07/16. eng).

85. Padilla S, Carden MF, Attridge RT, Burgess DS. In-vitro activity of colistin, amikacin and in combination against multi-drug resistant Acinetobacter baumannii in a pharmacodynamic-pharmacokinetic model model. 4th Annual Louis C Littlefield Celebrating Pharmacy Research Excellence Day in Professional, Graduate and Postgraduate Programs. Austin: University of Texas, April 172008.

86. Corvec S, Tafin UF, Betrisey B, Borens O, Trampuz A. Activities of fosfomycin, tigecycline, colistin, and gentamicin against extendedspectrum-beta-lactamase-producing Escherichia coli in a foreign-body infection model. Antimicrob Agents Chemother. 2013;57(3):1421-7.

87. Gordon NC, Png K, Wareham DW. Potent synergy and sustained bactericidal activity of a 
vancomycin-colistin combination versus multidrug-resistant strains of Acinetobacter baumannii. Antimicrob Agents Chemother. 2010;54(12):5316-22.

88. Wareham DW, Gordon NC, Hornsey M. In vitro activity of teicoplanin combined with colistin versus multidrug-resistant strains of Acinetobacter baumannii. J Antimicrob Chemother. 2011;66(5):1047-51 (Epub 2011/03/12. eng).

89. Vidaillac C, Benichou L, Duval RE. In vitro synergy of colistin combinations against colistin-resistant Acinetobacter baumannii, Pseudomonas aeruginosa, and Klebsiella pneumoniae isolates. Antimicrob Agents Chemother. 2012;56(9):4856-61.

90. Betts JW, Phee LM, Hornsey M, Woodford N, Wareham DW. In vitro and in vivo activity of tigecycline/colistin combination therapies against carbapenem resistant Enterobacteriaceae. Antimicrob Agents Chemother. 2014;58(6):3541-6.

91. Liu B, Liu Y, Di X, Zhang X, Wang R, Bai Y, et al. Colistin and anti-Gram-positive bacterial agents against Acinetobacter baumannii. Rev Soc Bras Med Trop. 2014;47(4):451-6 (Epub 2014/09/18. eng).

92. Percin D, Akyol S, Kalin G. In vitro synergism of combinations of colistin with selected antibiotics against colistin-resistant Acinetobacter baumannii. GMS Hyg Infect Control. 2014;9(2):Doc14 (Epub 2014/08/26. eng).

93. Pournaras S, Vrioni G, Neou E, Dendrinos J, Dimitroulia E, Poulou A, et al. Activity of tigecycline alone and in combination with colistin and meropenem against Klebsiella pneumoniae carbapenemase (KPC)-producing Enterobacteriaceae strains by time-kill assay. Int J Antimicrob Agents. 2011;37(3):244-7.

94. Albur M, Noel A, Bowker K, MacGowan A. Bactericidal activity of multiple combinations of tigecycline and colistin against NDM-1-producing Enterobacteriaceae. Antimicrob Agents Chemother. 2012;56(6):3441-3.

95. Demiraslan H, Dinc G, Ahmed SS, Elmali F, Metan G, Alp E, et al. Carbapenem-resistant Klebsiella pneumoniae sepsis in corticosteroid receipt mice: tigecycline or colistin monotherapy versus tigecycline/colistin combination. J Chemother. 2014;26(5):276-81

96. Michail G, Labrou M, Pitiriga V, Manousaka S, Sakellaridis N, Tsakris A, et al. Activity of tigecycline in combination with colistin, meropenem, rifampin, or gentamicin against KPC-producing Enterobacteriaceae in a murine thigh infection model. Antimicrob Agents Chemother. 2013;57(12):6028-33.
97. Yilmaz EM, Sunbul M, Aksoy A, Yilmaz H, Guney AK, Guvenc T. Efficacy of tigecycline/colistin combination in a pneumonia model caused by extensively drug-resistant Acinetobacter baumannii. Int J Antimicrob Agents. 2012;40(4):332-6.

98. Souli M, Galani I, Boukovalas S, Gourgoulis MG, Chryssouli Z, Kanellakopoulou K, et al. In vitro interactions of antimicrobial combinations with fosfomycin against KPC-2-producing Klebsiella pneumoniae and protection of resistance development. Antimicrob Agents Chemother. 2011;55(5):2395-7 (Epub 2011/02/16. eng).

99. Di X, Wang R, Liu B, Zhang X, Ni W, Wang J, et al. In vitro activity of fosfomycin in combination with colistin against clinical isolates of carbapenem-resistant Pseudomas aeruginosa. J Antibiot (Tokyo). 2015;68(9):551-5.

100. Safarika A, Galani I, Pistiki A, Giamarellos-Bourboulis EJ. Time-kill effect of levofloxacin on multidrug-resistant Pseudomonas aeruginosa and Acinetobacter baumannii: synergism with imipenem and colistin. Eur J Clin Microbiol Infect Dis. 2015;34(2):317-23 (Epub 2014/09/07. eng).

101. Yang H, Chen G, Hu L, Liu Y, Cheng J, Li H, et al. In vivo activity of daptomycin/colistin combination therapy in a Galleria mellonella model of Acinetobacter baumannii infection. Int J Antimicrob Agents. 2015;45(2):188-91 (Epub 2014/12/03. eng).

102. Galani I, Orlandou K, Moraitou H, Petrikkos G, Souli M. Colistin/daptomycin: an unconventional antimicrobial combination synergistic in vitro against multidrug-resistant Acinetobacter baumannii. Int J Antimicrob Agents. 2014;43(4): 370-4.

103. Phee L, Hornsey M, Wareham DW. In vitro activity of daptomycin in combination with low-dose colistin against a diverse collection of Gram-negative bacterial pathogens. Eur J Clin Microbiol Infect Dis. 2013;32(10):1291-4 (Epub 2013/04/24. eng).

104. Phee LM, Betts JW, Bharathan B, Wareham DW. Colistin and fusidic acid: a novel potent synergistic combination for the treatment of multi-drug resistant Acinetobacter baumannii infections. Antimicrob Agents Chemother. 2015;59(8):4544-50.

105. Shields RK, Kwak EJ, Potoski BA, Doi Y, Adams-Haduch JM, Silviera FP, et al. High mortality rates among solid organ transplant recipients infected with extensively drug-resistant Acinetobacter baumannii: using in vitro antibiotic combination testing to 
identify the combination of a carbapenem and colistin as an effective treatment regimen. Diagn Microbiol Infect Dis. 2011;70(2):246-52 (Epub 2011/03/01. eng).

106. Levin AS. Multiresistant Acinetobacter infections: a role for sulbactam combinations in overcoming an emerging worldwide problem. Clin Microbiol Infect. 2002;8(3):144-53 (Epub 2002/05/16. eng).

107. Corbella X, Ariza J, Ardanuy C, Vuelta M, Tubau F, Sora $\mathrm{M}$, et al. Efficacy of sulbactam alone and in combination with ampicillin in nosocomial infections caused by multiresistant Acinetobacter baumannii. J Antimicrob Chemother. 1998;42(6):793-802 (Epub 1999/03/03. eng).

108. Svetitsky S, Leibovici L, Paul M. Comparative efficacy and safety of vancomycin versus teicoplanin: systematic review and meta-analysis. Antimicrob Agents Chemother. 2009;53(10): 4069-79.

109. Cavalcanti AB, Goncalves AR, Almeida CS, Bugano DD, Silva E. Teicoplanin versus vancomycin for proven or suspected infection. Cochrane Database Syst Rev. 2010;6:CD007022.

110. Imberti R, Cusato M, Villani P, Carnevale L, Iotti GA, Langer M, et al. Steady-state pharmacokinetics and BAL concentration of colistin in critically Ill patients after IV colistin methanesulfonate administration. Chest. 2010;138(6):1333-9 (Epub 2010/06/19. eng).

111. Plachouras D, Karvanen M, Friberg LE, Papadomichelakis E, Antoniadou A, Tsangaris I, et al. Population pharmacokinetic analysis of colistin methanesulphonate and colistin after intravenous administration in critically ill patients with gram-negative bacterial infections. Antimicrob Agents Chemother. 2009;53:3430-6 (Epub 2009/05/13. Eng).

112. Markou N, Markantonis SL, Dimitrakis E, Panidis D, Boutzouka E, Karatzas S, et al. Colistin serum concentrations after intravenous administration in critically ill patients with serious multidrug-resistant, gram-negative bacilli infections: a prospective, open-label, uncontrolled study. Clin Ther. 2008;30(1):143-51 (Epub 2008/03/18. eng).

113. Mah TF, O'Toole GA. Mechanisms of biofilm resistance to antimicrobial agents. Trends Microbiol. 2001;9(1):34-9 (Epub 2001/02/13. eng).

114. Stressmann FA, Rogers GB, Marsh P, Lilley AK, Daniels TW, Carroll MP, et al. Does bacterial density in cystic fibrosis sputum increase prior to pulmonary exacerbation? J Cyst Fibros. $2011 ; 10(5): 357-65$.

115. Pachon-Ibanez ME, Docobo-Perez F, Lopez-Rojas $\mathrm{R}$, Dominguez-Herrera J, Jimenez-Mejias ME, Garcia-Curiel A, et al. Efficacy of rifampin and its combinations with imipenem, sulbactam, and colistin in experimental models of infection caused by imipenem-resistant Acinetobacter baumannii. Antimicrob Agents Chemother. 2010;54(3):1165-72 (Epub 2010/01/06. eng).

116. Montero A, Ariza J, Corbella X, Domenech A, Cabellos C, Ayats J, et al. Antibiotic combinations for serious infections caused by carbapenem-resistant Acinetobacter baumannii in a mouse pneumonia model. J Antimicrob Chemother. 2004;54(6):1085-91 (Epub 2004/11/ 18. eng).

117. Pantopoulou A, Giamarellos-Bourboulis EJ, Raftogannis M, Tsaganos T, Dontas I, Koutoukas $\mathrm{P}$, et al. Colistin offers prolonged survival in experimental infection by multidrug-resistant Acinetobacter baumannii: the significance of co-administration of rifampicin. Int $\mathrm{J}$ Antimicrob Agents. 2007;29(1):51-5 (Epub 2006/12/26. eng).

118. Cirioni O, Ghiselli R, Orlando F, Silvestri C, Mocchegiani F, Rocchi $M$, et al. Efficacy of colistin/rifampin combination in experimental rat models of sepsis due to a multiresistant Pseudomonas aeruginosa strain. Crit Care Med. 2007;35(7):1717-23 (Epub 2007/04/25. eng).

119. Giacometti A, Cirioni O, Ghiselli R, Orlando F, Mocchegiani F, D'Amato G, et al. Antiendotoxin activity of antimicrobial peptides and glycopeptides. J Chemother. 2003;15(2):129-33 (Epub 2003/06/12. eng).

120. Dinc G, Demiraslan H, Elmali F, Ahmed SS, Alp E, Doganay M. Antimicrobial efficacy of doripenem and its combinations with sulbactam, amikacin, colistin, tigecycline in experimental sepsis of carbapenem-resistant Acinetobacter baumannii. New Microbiol. 2015;38(1):67-73 (Epub 2015/03/06. eng).

121. Zak O, O'Reilly $\mathrm{T}$. Animal models in the evaluation of antimicrobial agents. Antimicrob Agents Chemother. 1991;35(8):1527-31 (Epub 1991/08/01. eng).

122. Dinc G, Demiraslan H, Elmali F, Ahmed SS, Metan G, Alp E, et al. Efficacy of sulbactam and its combination with imipenem, colistin and tigecycline in an experimental model of carbapenem-resistant Acinetobacter baumannii sepsis. Chemotherapy. 2014;59(5):325-9. 
123. Hornsey M, Wareham DW. In vivo efficacy of glycopeptide-colistin combination therapies in a Galleria mellonella model of Acinetobacter baumannii infection. Antimicrob Agents Chemother. 2011;55(7):3534-7.

124. Hornsey M, Phee L, Longshaw C, Wareham DW. In vivo efficacy of telavancin/colistin combination therapy in a Galleria mellonella model of Acinetobacter baumannii infection. Int $\mathrm{J}$ Antimicrob Agents. 2013;41(3):285-7.

125. Dalfino L, Puntillo F, Mosca A, Monno R, Spada ML, Coppolecchia $S$, et al. High-dose, extended-interval colistin administration in critically ill patients: is this the right dosing strategy? A preliminary study. Clin Infect Dis. 2012;54(12):1720-6 (Epub 2012/03/17. eng).

126. Falagas ME, Rafailidis PI, Ioannidou E, Alexiou VG, Matthaiou DK, Karageorgopoulos DE, et al. Colistin therapy for microbiologically documented multidrug-resistant Gram-negative bacterial infections: a retrospective cohort study of 258 patients. Int $\mathrm{J}$ Antimicrob Agents. 2010;35(2):194-9 (Epub 2009/12/17. eng).

127. Elias LS, Konzen D, Krebs JM, Zavascki AP. The impact of polymyxin B dosage on in-hospital mortality of patients treated with this antibiotic. J Antimicrob Chemother. 2010;65(10):2231-7 (Epub 2010/08/06. eng).

128. Qureshi ZA, Paterson DL, Potoski BA, Kilayko MC, Sandovsky G, Sordillo E, et al. Treatment outcome of bacteremia due to KPC-producing Klebsiella pneumoniae: superiority of combination antimicrobial regimens. Antimicrob Agents Chemother. 2012;56(4):2108-13.
129. Zarkotou O, Pournaras S, Tselioti P, Dragoumanos V, Pitiriga V, Ranellou K, et al. Predictors of mortality in patients with bloodstream infections caused by KPC-producing Klebsiella pneumoniae and impact of appropriate antimicrobial treatment. Clin Microbiol Infect. 2011;17(12):1798-803.

130. Tumbarello M, Viale P, Viscoli C, Trecarichi EM, Tumietto F, Marchese A, et al. Predictors of mortality in bloodstream infections caused by Klebsiella pneumoniae carbapenemase-producing K. pneumoniae: importance of combination therapy. Clin Infect Dis. 2012;55(7):943-50.

131. Dubrovskaya Y, Chen TY, Scipione MR, Esaian D, Phillips MS, Papadopoulos J, et al. Risk factors for treatment failure of polymyxin B monotherapy for carbapenem-resistant Klebsiella pneumoniae infections. Antimicrob Agents Chemother. 2013;57(11):5394-7.

132. Linden PK, Kusne S, Coley K, Fontes P, Kramer DJ, Paterson D. Use of parenteral colistin for the treatment of serious infection due to antimicrobial-resistant Pseudomonas aeruginosa. Clin Infect Dis. 2003;37(11):e154-60 (Epub 2003/11/14. eng).

133. Furtado GHC, d'Azevedo PA, Santos AF, Gales AC, Pignatari ACC, Medeiros EAS. Intravenous polymyxin $\mathrm{B}$ for the treatment of nosocomial pneumonia caused by multidrug-resistant Pseudomonas aeruginosa. Int J Antimicrob Agents. 2007;30(4):315-9. 